\title{
Overtime Work as a Signaling Device
}

\author{
Silke Anger \\ German Institute for Economic Research (DIW Berlin)
}

February 2006

\begin{abstract}
This paper adds to the various reasons for a worker's supply of overtime hours by focusing on forward-looking labor supply, and provides an explanation for the empirically proven relationship between overtime and positive future outcomes. We suggest an internal signaling model, in which a worker signals his value to the employer by supplying unpaid overtime. The possible benefits from signaling by means of longer hours are promotion and job retention. We analyze whether overtime, and in particular unpaid overtime, can be an effective signaling device for a higher value, and derive the conditions for a separating and a pooling equilibrium. In the empirical part of the analysis, we examine whether overtime has in fact a signaling component. Variations in collectively bargained hours between industries are exploited, as they imply different overtime thresholds for workers with the same number of actual hours. Using data from the German Socio-Economic Panel Study (SOEP) for the years 1993 to 2004, support is found for the signaling hypothesis for West German workers, whereas negative signaling was found to prevail in East Germany.
\end{abstract}

Keywords: $\quad$ Asymmetric information, Internal signaling, Overtime

JEL classification: J22, D82, J41

I would like to thank Ronald Bachmann, Michael C. Burda, Bob Hart, and seminar participants at the Humboldt University Berlin, University of Stirling, and Berlin Network of Labor Research. All remaining errors are mine. Corresponding address: Silke Anger, DIW Berlin, Department "German Socio-Economic Panel Study", Königin-LuiseStr. 5, 14195 Berlin, Germany, Phone (Fax): +49-30-89789-526 (109), E-mail: sanger@diw.de. 


\section{Introduction}

In virtually all modern economies a considerable fraction of the working population performs overtime hours, and many workers supply their extra hours for free ${ }^{1}$. Unpaid work is one of the most fascinating forms of working time, as the supply of uncompensated working hours is conflicting with both standard economic theory and intuition. Consequently, the question arises as to why many workers offer unpaid hours. We add to the various explanations why workers might want to provide extra hours by focusing on forward-looking labor supply (Bell and Freeman, 2001). We suggest an internal signaling model, in which workers might try to signal a higher value to the firm by supplying unpaid overtime. The possible benefits from signaling by means of longer hours are promotion and job retention, i.e. not being laid off. In this study, we investigate both theoretically and empirically, whether overtime, and in particular unpaid overtime, can be an effective signaling device for a higher value. This might have important implications for the structure of the workforce and firm hierarchies, and explain wage differentials that may not be attributed to differences in productivities. If overtime turns out to have a signaling component, worker groups who are constrained in their signaling abilities, such as women with family responsibilities, workers with health constraints, or persons in workplaces which do not allow for voluntary extra hours, would be disadvantaged even if they were equally productive. In addition, overtime signaling implies potential inefficiencies, since the signaling component of overtime does not add to productivity. Therefore, a reduction in overtime by its signaling part may have welfareenhancing effects.

The following section provides an overview of forward-looking labor supply and summarizes previous research. Section 3 gives an introduction to the signaling model and provides an intuitive explanation of the internal signaling game. Section 4 presents the theoretical model, derives the pooling and separating equilibria, and conducts an analysis of welfare effects. Section 5 proposes an empirical identification strategy to test the signaling model. It describes the data and the estimation methodology, and presents the results. Section 6 concludes.

\footnotetext{
${ }^{1}$ According to data from the German Socio-Economic Panel Study (SOEP), about $15 \%$ of the German full-time employees worked unpaid overtime in 2004. This percentage is even higher for the U.K. and the Netherlands (European Commission, 2003).
} 


\section{Forward-Looking Labor Supply}

\subsection{Reasons for Unpaid Overtime}

The remarkable increase in unpaid overtime, which can be observed in Germany, and to an even greater extent in the U.K., raises the question as to why workers are willing to supply uncompensated hours. The reasons might be demand driven, such as constant pressure from the firm side or managing of demand peaks, but also supply driven, or a combination of both. ${ }^{2}$ Bell and Hart (1999) and, in a subsequent study, Bell, Hart, Hübler, and Schwerdt (2000) provide various explanations for the existence of unpaid overtime hours. One of their hypotheses is that extra hours might be prevalent in jobs with uncertainty about the required time to complete complex tasks, where contracts with a standard workweek are not feasible. Another explanation is that unpaid overtime hours can be used by unproductive workers to catch up with their more productive colleagues. Completing certain job tasks during extra hours enables them to understate the working time actually taken, and therefore to build a good reputation. Furthermore, Bell and Hart (1999) suggest that workers with leadership roles might have to compensate for absenteeism of their team members, which results in long workweeks. Another explanation is that managers might regard unpaid overtime as gift in exchange for a high wage. However, all these explanations implicitly provide a more or less ample scope for the worker to decide on the amount of overtime hours he wants to supply. Even if the available options are limited and constrained by the operation of background conditions, there is a certain degree of freedom over the number of hours that a worker wishes to supply without receiving direct compensation (Campbell, 2002). Therefore, we focus our study on the labor supply side, and take the demand for unpaid overtime as given.

\subsection{Unpaid Overtime and Future Returns}

Our focus on the investment character of overtime is supported by empirical findings for Great Britain by Campbell and Green (2002) who reveal that there are positive though diminishing longterm returns from working longer hours, unpaid hours having the greatest impact. Empirical evidence for the investment character of overtime has been also provided by Booth, Francesconi, and Frank (2003) who show for the U.K. that the amount of overtime correlates with subsequent promotions in a significantly positive way. Supportive empirical evidence for the investment

\footnotetext{
${ }^{2}$ Böckerman and Jäntti (2004) and Bryan (2004) provide evidence for both labor supply and demand being important for the variation of working hours.
} 
character of unpaid extra hours is given by Pannenberg (2005) who investigates long-term effects of unpaid overtime work in West Germany. He finds that there are substantial long-term labor earnings effects associated with cumulative average unpaid overtime, which is evidence for the importance of investing in current working hours beyond the standard workweek to enhance real earnings prospects. He shows that workers with at least some incidence of unpaid overtime experience the highest wage growth. Meyer and Wallette (2004) do not find evidence for future benefits from working overtime. Their analysis on temporary workers in Sweden reveals that overtime has no effect on the transition from temporary jobs to open-ended jobs. Therefore, it might only pay for some worker groups to invest in extra hours in order to get some future benefit. The analysis of regional unemployment and overtime by Anger (2005a) shows a positive relationship between regional unemployment rates and unpaid overtime hours for male workers in West Germany. This might indicate that these workers provide unpaid overtime to prevent a job loss, and that their labor supply may hence be forward-looking. Only weak evidence for the investment character of overtime was found by Anger (2005b), which revealed a weak, but positive relationship between unpaid hours and the probability of promotion and pay rise for male workers.

Even though the relationship between working hours and positive future outcomes has been confirmed by many studies, it is not clear how the link between overtime hours and future payoffs exactly looks like. It might be simply the cost aspect that leads firms to choose overtime workers to be promoted or retained in the firm, since they provide cheap labor to their employer. This is not only true for the case of unpaid overtime, but also for paid overtime, since by using overtime, firms can adjust labor at the inner margin, and therefore save fixed or sunk costs that would arise in the case of additional hirings. Furthermore, higher wages for overtime workers might be interpreted as a reward in the sense of gift exchange. Some studies even use the amount of overtime, or working hours more generally, as direct measure of effort (Engellandt and Riphahn, 2004, 2003; Bratti and Staffolani, 2004), which may result in future payoffs in form of deferred compensation. Another explanation mentioned in the literature is that extra working time in the firm might not only be used for additional productive hours, but also to acquire specific human capital (Booth et al., 2003) which yields a return later on. Lastly, overtime hours might be neither fully productive nor entirely used for human capital accumulation, but serve as a signal for motivation, flexibility, productivity, or loyalty to the employer (Meyer and Wallette, 2004). Campbell and Green (2002) point out that a positive link between past hours and current earnings is consistent with either a human capital or a signaling model. 


\subsection{Overtime Signaling}

In this study, we take up the idea of extra hours serving as a signal, suggesting that overtime does not necessarily add to the production of output, nor does it need to be used for human capital accumulation, and still might yield positive future return to workers. To expound this argument, we provide a signaling framework to explain the link between unpaid overtime work and future payoffs. By working long hours, the employee might signal to his employer that he is of high value, which might take the form of high effort, commitment, or motivation. We argue that these extra hours do not have to be used productively in the firm, and at the extreme, might be regarded as leisure at the workplace. This view is closely related to the notion of presenteeism or 'display overtime', which means that employees work excessive hours in order to be seen, even if there is no extra work to do (Simpson, 1998).

The extension of Spence's (1973) signaling model leads us to an internal signaling game in the firm with unpaid overtime as signaling device for the high value of a worker. The question is whether overtime can serve as a signal "that would carry information persistently in equilibrium [...] from those with more to those with less information" (Spence, 2002), and thus credibly convey information to the firm. The objective of this study is, therefore, to show that otherwise useless overtime may serve as a signal of unobservable worker value, and to find equilibria in which highvalue workers choose to work more unpaid overtime than low-value workers, and where firms correctly take the differences in overtime as signal of a worker's value. We investigate the welfare effects which are ambiguous due to the trade off between optimal human resource allocation and individually optimal working hours. On the one hand, the revealing of information about the worker's value can lead to a more efficient allocation of labor, e.g. by the promotion of the most productive people. Therefore, in some instances, Pareto improvements compared to the no-signaling case might be reached, even if overtime does not add further output to the firm's production process. On the other hand, signaling is costly for workers, and their welfare might be reduced if they are compelled to invest in a high level of signaling activity. This is in line with the argument of Sousa-Poza and Ziegler (2002) who focus on the recruitment process and show in their model of labor contracting that inefficiently long working hours can be explained by asymmetric information. The same argument is put forward by Landers, Rebitzer, and Taylor (1996) who explain promotion decisions on the basis of long working hours as screening device for low disutility of work. Their result is that the employer's demand for excessive hours leads to inefficiencies in the sense of Akerlof's (1976) overwork equilibrium. Unlike in Landers et al. (1996), in the present study, productivity is not necessarily assumed to be constant across workers, and firms are supposed to sort between high- and low-value workers instead of only selecting hard-working persons. 


\section{Internal Signaling Game}

\subsection{Information Asymmetry in the Firm}

Our explanation of signaling is analogue to that of the signaling theory by Spence (1973) which was originally applied to the problem of asymmetric information in the job recruiting process. Since the employer has no information on the job performance of an applicant prior to the hiring, he relies on education as signal in order to proxy the applicant's productivity. In the present study, we argue that even after the hiring process, the firm has no full information on the true productivity of a worker, if there are positive monitoring costs. The similarity to the job signaling model is that there are attributes of employees which are unobservable to the employer, and which affect the worker's current and subsequent value to the firm. This information asymmetry leads to the phenomenon that firms take human resources decisions, such as decisions on promotions or layoffs, on the basis of characteristics, e.g. unpaid overtime hours, which are easier to observe than productivity or other valuable worker attributes. Spence (1974) himself thought of a wider application of his original idea, suggesting "a range of quasi-market selective screening phenomena, ranging from college admissions to promotion in large organizations, that have the informational structure of the job market and hence can usefully be viewed through the same conceptual lens."

The important extension of the original signaling model is that we assume imperfect information after the recruiting process in the sense that the employer does not know the true value of the worker, although the latter is already employed in the firm. This might be the case if individual monitoring is difficult due to team work, or if high costs arise from monitoring. ${ }^{3}$ Even if a worker stays within the same firm for a longer time period, there is uncertainty on the worker's true value at least to some extent, although information is likely to become more symmetric over time due to employer learning. The firm is naturally interested in employing high-quality workers because a remuneration according to the contracted wage above their product would incur a loss to the firm. Knowing that the employer has incomplete information, the worker will invest in "observable characteristics attached to the individual that are subject to manipulation by him" (Spence, 1973). Given that workers know by which routine they are evaluated for promotions, pay rises or layoffs, they will invest in those activities which are taken as signals for high value. However, workers of low quality have an incentive to mimic high-quality workers because they run the risk of being laid off, which means that they would have to enter unemployment, or start in another firm at a relatively low wage as compared to the option of receiving a pay rise in the initial firm. For the

\footnotetext{
${ }^{3}$ This is supported by Heywood, Hübler, and Jirjahn (1998) who state that correct performance measurement of output is related to considerable costs involved in designing the right measurement system.
} 
signal to be effective, it must significantly affect the probabilistic evaluations of the workers' values.

\subsection{The Signal of the Worker's Value}

The basic assumption of our model is that unpaid overtime signals the worker's value to the firm. This value may be derived from a number of worker characteristics, one of them being productivity, measured by human capital and unobserved ability. However, even high-ability workers might be of low value if they have a low taste for work, which may result in low effort, motivation, and commitment to the job. Hence, the overall quality of a worker has multiple dimensions. ${ }^{4}$ It might also be influenced by physical or social constraints of the worker, such as health constraints or family responsibilities, since restrained workers are less likely to help out in emergency situations. Therefore, overtime might also signal an option value, as workers who are currently putting in long hours are likely to be similarly available for long hours in the future. Since all these characteristics are beneficial to the employer, they will be merely referred to as the worker's value to the firm. In addition, the multiple dimensions of a worker's quality might be interdependent. For instance, there is evidence for a low disutility of work being related to worker productivity, as high-ability workers find it easier to work an extra hour than do low-ability workers. "A behavioral explanation for this view is that people who like their job tend to be good at it, and vice versa" (Sousa-Poza and Ziegler, 2002). Accordingly, overtime might serve as a signaling device to select both productive and motivated workers instead of workers with long hours per se. Similarly, Ichino and Muehlheusser (2003) focus on heterogeneous workers with respect to the cost of exerting effort. They refer to the supporting evidence found in the studies of Nagin, Rebitzer, Sanders, and Taylor (2002) and Ichino and Riphahn (2003) who show that high-ability workers have the least cost of exerting effort. Of course, a firm prefers workers with both high productivity and low disutility of work, but among equally productive workers, it would choose the ones with low disutility.

The negative relationship between the cost of working overtime and the value of a worker is crucial to the model because only then, the firm can require high levels of unpaid overtime as a means to deter low-value workers from pretending to be of high-value type. If all workers were equally productive and faced the same constraints, the firm could derive the relative value of a worker directly from the worker's disutility of labor. However, since other worker attributes are important, the cost of working extra hours and the worker's value are just positively associated. For an

\footnotetext{
${ }^{4}$ This is similar to the education signaling model of Streb (2002) who assumes two-dimensional asymmetric information, and differentiates between competency and character.
} 
employer to have assessments over the productive capacity of a worker for a given level of observed unpaid overtime, he needs previous experience in the market. This means that he relates the observed number of overtime hours to his later information on the workers' quality, which will be at least partially revealed after a certain period of time. Therefore, the signaling period cannot last forever, as there is likely to be more and more information available to the employer over time. However, as long as there is uncertainty on the workers' true productivity at least to some extent, there is scope for the signaling game. The signaling equilibrium is characterized by the following features: First, workers take a rational decision on how much unpaid hours to work, given the returns and the costs of working extra hours. Second, the firm's expectations based on past experience, must be confirmed by subsequent experience. The employer decides on his promotion and layoff strategies according to his beliefs, which again affect the worker's decisions with respect to the optimal amount of overtime. When the true value of a worker is revealed over time, the firm's beliefs must be self-confirming.

Therefore, even if one assumes that unpaid overtime work is not fully productive, there is a positive effect evolving from signaling activities. The revelation of a worker's type by relying on signals can help to reach a more efficient allocation of labor. However, there is also a downside of the signaling game due to the countervailing effect arising from overinvestment in the signal. If unpaid hours are taken as a signal, workers invest in them and bear the cost in the form of disutility of work. Therefore, a trade-off emerges between efficiency gains and negative welfare effects stemming from higher costs of working overtime. The crucial question is therefore whether it is beneficial not to rely on potential signals in order to avoid the losses in welfare. If the signaling game has multiple equilibria with different extents of overinvestment, a control over an excessive utilization of the signal would be desirable in order to shift the equilibrium towards a lower level of investment while retaining the signal. This might be achieved by implementing taxes on overtime which lowers the overtime level without giving up the informational content of the signal.

\section{The Model}

\subsection{Model Set-Up}

We consider heterogeneous agents with respect to the value to the firm and the costs of working overtime, which arises from disutility of work. Out of a large number of profit-maximizing firms with the same production technologies we look at one firm that employs one worker who is either 
of high-value type $H$ with probability $\lambda$, or of low-value type $L$ with probability $(1-\lambda)$, where $\lambda$ $\in(0,1)^{5}$. The value $\theta$ of a high-value worker is higher than of a low-value worker: $\theta_{H}>\theta_{L}>0$. The model assumes two periods, the first being a trial period after which the firm decides on whether to employ the worker in the second, the tenure period. The product of a worker is time-invariant, which implies that there is no firm-specific human capital, which allows the worker's output to rise in the second period. Agents are assumed to be available for two periods, while firms have an infinite time horizon. We assume imperfect information in the firm in the sense that the employer does not know the true value of the worker. Knowing that the employer has incomplete information, the worker will invest in signaling activities that are supposed to inform the employer about the worker's high quality. In this model, extra hours serve as potential signal, and we assume that overtime has no effect on the worker's product in order to isolate the effect of signaling. Therefore, the only role of overtime is to convey information from the worker to the employer, which implies that there is no need for working overtime in the case of perfect information. Furthermore, we assume that there is no compensation for extra hours worked, and that the demand for overtime is completely elastic, which means that the worker himself can decide how many extra hours he wants to work.

Overtime work is available to the worker at a cost which can be interpreted as disutility of work, and depends on the worker value $\theta$, and the amount of overtime working $v, v \in \mathbb{R}$. The cost function $C$ is twice differentiable and has the following properties:

$$
\begin{aligned}
& C=C(v, \theta) \\
& C(0, \theta)=0, \quad C_{v}(v, \theta)>0, \quad C_{v, v}(v, \theta)>0, \quad C_{\theta}(v, \theta)<0 \text { for all } v>0, \\
& \text { and } C_{v, \theta}(v, \theta)<0 .
\end{aligned}
$$

Therefore, both worker types have a strictly increasing cost of working overtime, whereas both the cost and the marginal cost are lower for workers with high value. In other words, the overall quality of a worker and his disutility of working overtime are inversely related. This single-crossing property is crucial to the model in order to separate high-value and low-value workers, ${ }^{6}$ and can be

\footnotetext{
${ }^{5}$ We model explicitly only one employer-employee-relationship, but are aware that there are many firms with simultaneous single-worker games. In this case $\lambda$ might be thought of as a fraction of high-value workers in the market. Since all firms and all workers of the same type are assumed to be homogenous, the analysis of one employeremployee-relationship is sufficient.

${ }^{6}$ The concept of the single-crossing property, which is also known as Spence-Mirrlees condition, can be represented graphically by showing that indifference curves which represent preferences of the two worker types over pairs of overtime and wage levels cross only once. At the point of intersection, the indifference curve of the high-value worker has a smaller slope.
} 
justified with the conception in the real world that people who are good at their job have a smaller distaste to work (Sousa-Poza and Ziegler, 2002). ${ }^{7}$

In the following, we look at the particular cost function $C(v, \theta)=k \cdot \frac{v^{\alpha}}{\theta^{\beta}}$, with $\mathrm{k}>0, \alpha>1$, and $\beta>0$, which satisfies the properties in (1). Whereas $\alpha$ is the cost elasticity with respect to overtime hours, $\beta$ is the cost elasticity with respect to worker quality, and $k$ a scale parameter. The lifetime utility of a worker of type $\theta$ who chooses the overtime level $v$ in the trial period, ${ }^{8}$ and receives wage $W_{l}$ in the first, and $W_{2}$ in the second period is given by the utility function:

$$
U\left(W_{1}, W_{2}, v \mid \theta\right)=W_{1}-C(v, \theta)+\delta W_{2}(v)=W_{1}-k \cdot \frac{v^{\alpha}}{\theta^{\beta}}+\delta W_{2}(v)
$$

, $\delta$ being a discount factor with $\delta \in[0,1]$. The marginal rate of substitution between the tenure wage rate and overtime hours at any point is then $\frac{d W_{2}}{d v}=C_{v}(v, \theta)-\delta W_{2 v}(v)$, which is decreasing in $\theta$. Thus, the preferences of the worker satisfy the single-crossing property, which plays a key role in the model for the separation of high-value and low-value workers. We make the simplifying assumption that there is no income from home production. Hence, the worker selects $v$ in the first stage to maximize the difference between his lifetime income and the cost of obtaining the signal, working overtime. Using (1) and (2) we get the following first-order optimality conditions:

$$
\delta W_{2 v}\left(v^{*}\right)=C_{v}\left(v^{*}, \theta\right)=\alpha k \cdot \frac{v^{\alpha-1}}{\theta^{\beta}}
$$

In order to maximize the worker's lifetime utility, the marginal benefit of overtime must equal its marginal cost.

\subsection{No Signaling Case}

We assume that the firm can contract with the worker on an individual basis, which enables the employer to reward his worker by paying him more in the tenure period than the contracted wage in the first stage $W_{l}$. This would be achieved by retention, whereas the employer can also lay off the worker, if the latter's productivity is low. The wage offered by the firm in the first period cannot be negotiated downward. ${ }^{9}$ If the worker is laid off, he has the outside option $W_{0}$, which might be

\footnotetext{
${ }^{7}$ The argument can be even strengthened when looking at a longer time horizon by taking into account that in later periods a high-quality worker will be revealed as true high-quality type and given a higher wage. Therefore, high-value workers have lower net costs of working extra hours and can afford higher levels of the signal.

${ }^{8}$ There is no use for the worker of providing overtime in the second period, since only cost but no benefit accrues by working longer hours. Therefore, in the following we simply refer to overtime hours in the first period as $v$.

${ }^{9}$ If there was no downward wage rigidity, no worker would ever be laid off.
} 
unemployment benefits or another contracted wage, if he starts a trial period in a new firm: $W_{0} \leq W_{1}$. In the absence of the ability to signal, the firm cannot distinguish between workers of high-value and low-value type. He evaluates the worker according to his expected contribution to the total output of the firm:

$$
\bar{\theta}=\lambda \theta_{H}+(1-\lambda) \theta_{L}+u
$$

where the error term $u$ might cause variations in the average quality, even if the probability $\lambda$ of employing a high-value worker is unchanged. The estimated value is higher with a positive error term $u>0$, e.g. if there is a technology shock, or negative $u<0$, e.g. if all the good workers are hired away from the labor market, and the firm therefore gets a bad selection of workers. At the beginning of the game, the employer observes the present shock $\left(u_{0}\right)$, which is public information. According to his initial expectations $\left(\bar{\theta}_{0}\right)$, he pays the worker a wage $W_{l}$ in the trial period, for which holds: $\theta_{\mathrm{H}}>\mathrm{W}_{1}>\theta_{\mathrm{L}} \cdot{ }^{10}$ Since the productivity shock of the second period is not known yet, only the first period wage is contracted. Depending on the relation between the contracted wage and the updated estimated value of the worker at the end of the first stage $(\bar{\theta})$ in the presence of the new shock $\left(u_{1}\right)$, the firm follows different strategies $\mathrm{S}$ :

$$
S=\left\{\begin{array}{l}
S_{L} \text { if } \bar{\theta}<W_{1} \\
S_{R} \text { if } \bar{\theta} \geq W_{1}
\end{array}\right.
$$

where $S_{L}$ is layoff, and $S_{R}$ retention of the worker. If the contracted wage exceeds the estimated value, the firm is going to lay off the worker $\left(S_{L}\right)$, and newly employs another worker of expected value $\bar{\theta}$ at wage $\mathrm{W}_{2}=\bar{\theta}<\mathrm{W}_{1}$. However, the worker is going to be kept $\left(S_{R}\right)$ and eventually receives a pay rise, if the expected value exceeds the contracted wage level. In this case the firm sets the wage $W_{2}$ equal to $\bar{\theta}$. All possible job separations are therefore initiated by the employer, and caused by negative movements in the error term during the trial period. Hence, in the no signaling case, the firm's strategy depends on variations in the average quality of a worker due to variations in the error term, $S_{j}(u)$, with $j=L, R$. The probability that the estimated value of the worker is greater or equal to the contracted wage is denoted as: $\operatorname{Pr}\left(\bar{\theta} \geq W_{1}\right)=S_{R}(\Delta u>0)=\rho$. The retention probability corresponds to the probability of receiving a wage equal to $\bar{\theta}$ as a consequence of retention, and is greater, the lower the contracted wage $W_{l}$, and the higher is the positive shock in the trial period.

\footnotetext{
${ }^{10}$ It is important that $\mathrm{W}_{1}>\theta_{\mathrm{L}}$, since otherwise the employer can afford to keep any type of worker in the firm.
} 


\subsection{Signaling Case}

In the signaling case, the firm's prior beliefs about a worker's value equal the expected worker output. Therefore, the firm pays the worker the contractual wage $W_{l}$ in the first stage just like in the no signaling case, and has discretion over whom to layoff. However, the worker has the possibility to invest in overtime in order to signal his high value to the employer. On the basis of previous experience in the market, the firm has assessments over the productive capacity of a worker for a given level of overtime, which it observes during the first period. The firm's beliefs are:

$$
\theta=\left\{\begin{array}{l}
\theta_{L} \text { if } v<v^{*} \\
\theta_{H} \text { if } v \geq v^{*}
\end{array} \quad, v^{*} \text { being some positive cut-off. }{ }^{11}\right.
$$

Therefore, the firm can update its prior beliefs about the worker's value and pursues the following cut-off strategies S, dependent on the assessments of the worker's value:

$$
S=\left\{\begin{array}{l}
S_{L} \text { if } \theta=\theta_{L}, v<v^{*} \\
S_{R} \text { if } \theta=\theta_{H}, v \geq v^{*}
\end{array}\right.
$$

If the worker's overtime level is below the cut-off level, he is going to be laid off by the firm at the end of the first period, since then the firm identifies the worker as being of a low-quality type with a product below the contractual wage level. This means that in the second period the laid off worker receives unemployment benefits, or starts in a new firm at a new trial period wage. The firm newly employs another worker of expected value $\bar{\theta}$ at wage $\mathrm{W}_{2}=\bar{\theta}<\mathrm{W}_{1}$. In contrast, if the number of overtime hours chosen by the worker is equal to or exceeds the threshold level set by the company, the firm keeps the worker for the second period and promotes him to a higher wage level because the currently paid contractual wage is lower than the productivity of a high-value worker. The wage rate $W_{2}$ in the second period will be equal to the productivity of a high-value worker $\theta_{H \cdot}{ }^{12}$ If the utility-maximizing worker chooses an overtime level below the cut-off, $v<v^{*}$, he should choose $v$ $=0$. Consequently, if he chooses to work a number of overtime hours above the threshold level, $v \geq$ $v^{*}$, he should choose $v=v^{*}$. Figure 1 summarizes the human resource strategies of the firm according to the firm's beliefs.

\footnotetext{
${ }^{11}$ Banks and Sundaram (1998) show that the cut-off strategy can be an optimal strategy in a perfect Bayesian equilibrium.

${ }^{12}$ We assume that there is no firm-specific human capital, which allows the worker to increase his output in the second period.
} 
Figure 1: The Firm's Strategies According to its Beliefs

Firm's beliefs

\begin{tabular}{|l|c|c|}
\cline { 2 - 3 } \multicolumn{1}{c|}{ Firm's strategy $\mathrm{S}$} & No signaling case: $S(u)$ & Signaling case: $S(v)$ \\
\hline Retention $S_{R}$ if & $\bar{\theta}>\mathrm{W}_{1}, \Delta u>0$ & $\theta=\theta_{\mathrm{H}}, v \geq v^{*}$ \\
\hline Layoff $\mathrm{S}_{L}$ if & $\bar{\theta}<\mathrm{W}_{1}, \Delta u<0$ & $\theta=\theta_{\mathrm{L}}, v<v^{*}$ \\
\hline
\end{tabular}

\subsubsection{Perfect Bayesian Equilibrium}

The equilibrium concept is a perfect Bayesian equilibrium in pure strategies, where the strategy combination of the worker and the firm, and the belief structure of the firm are such that a worker cannot increase his total expected lifetime earnings by changing his first period choice, given the firm's strategies and beliefs, and a firm cannot increase its expected profit by following a different strategy given the worker's strategies and its beliefs. In the signaling equilibrium the worker makes a rational investment choice with respect to overtime, given the returns and the costs of working extra hours. The firm has certain beliefs about the relation between overtime and the worker's value, which are based on previous experience. For an equilibrium to exist, the firm's expectations must be consistent, which means that past experience must be confirmed with subsequent experience. The employer decides on the retention and layoff strategies according to his beliefs, which in turn affect the worker's investment decision that he takes according to the expected returns. In the end, the firm's beliefs must be self-confirming. Under asymmetric information with signaling, two types of equilibria might evolve: a pooling equilibrium, where the firm does not distinguish between high- and low-value workers, and a separating equilibrium, where high-value and low-value workers choose to provide a different number of overtime hours. Therefore, merely allowing for signaling does not guarantee to separate high-value from low-value workers. The negative relationship between the worker's quality and his cost of working overtime is a prerequisite for overtime to be an instrument to deter low-quality workers from pretending to be of a high-quality type. Figure 2 summarizes the stages of the game. 
Figure 2: Internal Signaling Game

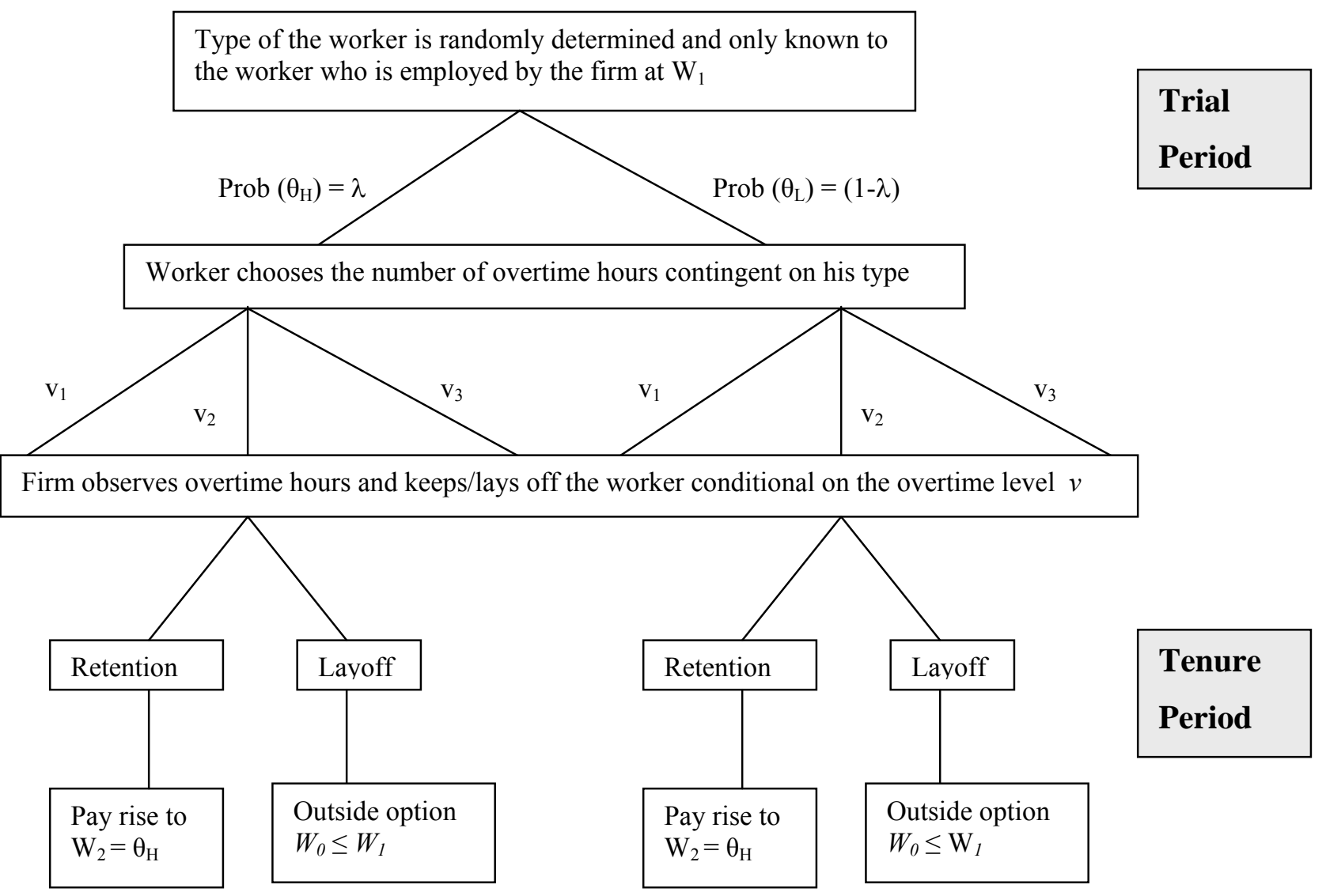

\subsubsection{Separating equilibrium}

For the firm's beliefs to be consistent with equilibrium play, we need: $v\left(\theta_{L}\right)<v^{*} \leq v\left(\theta_{H}\right)$. Only then, the firm can distinguish between workers with different quality types, and therefore is able to promote high-value workers to a higher wage $W_{2}$, and to lay off low-value workers who have to search for another job in order to receive a trial wage in another company, or obtain unemployment benefits. For low-value workers to choose zero overtime hours: $v\left(\theta_{L}\right)=0$ (and not $v^{*}$ ), the following condition must hold:

$$
\delta W_{0}>\delta W_{2}-k \cdot \frac{v^{\alpha}}{\theta_{L}^{\beta}}
$$

which results in an optimal overtime cut-off level $v^{*}>\left[\delta\left(W_{2}-W_{0}\right) \frac{\theta_{L}^{\beta}}{k}\right]^{\frac{1}{\alpha}}$. Therefore, in order to prevent low-value workers from supplying extra hours to the firm, the cut-off level must be higher, the higher the cost elasticity of worker quality $\beta$ and the difference between the wage of high-value and low-value workers $\left(W_{2}-W_{0}\right)$, and the lower the cost elasticity of overtime $\alpha$ and the scale parameter $k$. 
At the same time, high-value workers must choose a positive number of overtime hours: $v\left(\theta_{H}\right) \geq v^{*}$ $>0$. For this to be true we need:

$$
\delta W_{2}-k \cdot \frac{v^{\alpha}}{\theta_{H}^{\beta}} \geq \delta W_{0}
$$

and therefore, the optimal overtime cut-off level is: $v^{*} \leq\left[\delta\left(W_{2}-W_{0}\right) \frac{\theta_{H}^{\beta}}{k}\right]^{\frac{1}{\alpha}}$. As result, there exists a separating equilibrium in which the low-value worker sets $v=0$, and the high-value worker chooses $v=v^{*}$ for every:

$$
\left[\delta\left(W_{2}-W_{0}\right) \frac{\theta_{L}^{\beta}}{k}\right]^{\frac{1}{\alpha}}<v^{*} \leq\left[\delta\left(W_{2}-W_{0}\right) \frac{\theta_{H}^{\beta}}{k}\right]^{\frac{1}{\alpha}}
$$

Therefore, we end up with an infinite number of equilibria with a higher investment in overtime than there would be in the case of full information. In the separating equilibrium, high-value workers perform more overtime hours than if the low-value workers were not present. This result is inefficient in the sense that the investment in extra hours uses up resources without improving productivity. The equilibria can be distinguished by their level of dissipation of resources, and therefore graded by the Pareto criterion. Since a higher number of overtime hours worked $v^{*}$ does not improve the quality of sorting, but increases costs for the worker, this would lead to a Pareto inferior equilibrium. For the most efficient signaling equilibrium to materialize, a minimum cut-off has to be chosen: $v^{*}=\left[\delta\left(W_{2}-W_{0}\right) \frac{\theta_{L}^{\beta}}{k}\right]^{\frac{1}{\alpha}}$. However, the Pareto dominated equilibria are maintained because high-value workers are afraid of being taken as low-value type if they choose overtime lower than the cut-off level, and in equilibrium these beliefs are never disconfirmed.

\subsubsection{Pooling equilibrium}

In the pooling equilibrium case, the firm might belief that low levels of the signal are obtained by both, high-quality and low-quality workers. Therefore, the assumed productivity of the worker equals:

$$
\theta= \begin{cases}\bar{\theta} & \text { if } v<v^{*} \\ \theta_{H} & \text { if } v \geq v^{*}\end{cases}
$$

and the firm follows the strategy S with: 


$$
S= \begin{cases}\rho \cdot S_{R}+(1-\rho) \cdot S_{L} & \text { if } v<v^{*} \\ S_{R} & \text { if } v \geq v^{*}\end{cases}
$$

where a retention $S_{R}$ means that his wage rises to $W_{2}$, whereas a layoff $S_{L}$ means that he receives the outside option wage $W_{0}$. The retention probability $\rho$ is the probability that the estimated value of the worker is greater or equal to the contracted wage: $\operatorname{Pr}\left(\bar{\theta} \geq W_{1}\right) \cdot{ }^{13}$ As consequence, a high-value worker also sets $v=0$ if $v^{*}>\left[(1-\rho) \delta\left(W_{2}-W_{0}\right) \frac{\theta_{H}^{\beta}}{k}\right]^{\frac{1}{\alpha}} \cdot{ }^{14}$

This inequality is more likely to be true for a low cost elasticity of quality $\beta$, for a small difference between the wage of high-quality and low-quality workers $\left(W_{2}-W_{0}\right)$, for a high cost elasticity of overtime $\alpha$, for a high scale parameter $k$, and for a high probability $\rho$ of being kept within the firm. The latter is equal to the probability that the expected value exceeds the contractual wage, and is greater, the higher the productivity shock in the trial period, and the lower the contractual wage $W_{l}$. However, since $W_{1}$ is the upper bound for the outside option wage $W_{0}$, and since a smaller difference between $W_{2}$ and $W_{0}$ could be realized with a higher contractual wage $W_{l}$, the effect of the trial period wage might be ambiguous. As a result, the firm's beliefs may lead to an equilibrium, where none of the workers performs overtime hours, since the cut-off level is even too high for high-value workers.

Alternatively, the firm might believe that both high-value workers and low-value workers choose to work a positive amount of overtime hours and, therefore, that the worker's value is:

$$
\theta= \begin{cases}\theta_{L} & \text { if } v<v^{*} \\ \bar{\theta} & \text { if } v \geq v^{*}\end{cases}
$$

which would entail the following strategy:

$$
S= \begin{cases}S_{L} & \text { if } v<v^{*} \\ \rho \cdot S_{R}+(1-\rho) \cdot S_{L} & \text { if } v \geq v^{*}\end{cases}
$$

\footnotetext{
${ }^{13}$ This probability equals the retention probability for all workers in the no signaling case.

${ }^{14} \mathrm{~A}$ high-value worker will choose zero overtime hours if: $\delta W_{2}-k \cdot \frac{v^{\alpha}}{\theta_{H}^{\beta}}<\delta\left[\rho W_{2}+(1-\rho) W_{0}\right]$.
} 
In this case, a low-value worker also sets $v=v^{*}$ if $v^{*}<\left[\rho \delta\left(W_{2}-W_{0}\right) \frac{\theta_{L}^{\beta}}{k}\right]^{\frac{1}{\alpha}} \cdot 15$

This is more likely for a low cost elasticity of overtime $\alpha$, for a small cost function parameter $k$, for a large difference between the wage of high-value and low-value workers $\left(W_{2}-W_{0}\right)$, and for a high probability $\rho$ of being retained, i.e. for a high productivity shock in the trial period, and a low contractual wage $W_{1}$. As a result systematic overinvestment takes place, since both high-quality and low-quality workers decide to work overtime. This means that there is no sufficient correlation between the signaling costs and the expected product, and overtime can never be an effective signal with these beliefs. What becomes clear is that the single-crossing property is necessary but not sufficient to ensure that the right people signal quality. It is evident that the pooling equilibrium, where workers of both value type decide not to work overtime is Pareto superior to any other pooling equilibrium with positive overtime hours, the result being exactly the same as in the no signaling case.

\subsubsection{Welfare Analysis}

In the absence of signaling, everybody is retained or laid off according to his expected value, and therefore, according to (4) and (5) expects a tenure wage of $\rho \cdot W_{2}+(1-\rho) \cdot W_{0}$ independent of his quality type. Compared to the no signaling case, a low-value worker is worse off in both the separating equilibrium and in the pooling equilibrium because he receives a lower wage as soon as signaling takes place. In contrast, the high-value worker is better off in the separating equilibrium, if:

$$
\delta W_{2}-k \cdot \frac{v^{\alpha}}{\theta_{H}^{\beta}}>\delta\left(\rho \cdot W_{2}+(1-\rho) \cdot W_{0}\right)
$$

This holds if $1-\rho \geq\left(\frac{\theta_{L}}{\theta_{H}}\right)^{\beta}$ in a separating equilibrium with the minimum cut-off level approximating zero. Therefore, the high-value worker is better off in the separating equilibrium, if the probability $\rho$ of being promoted is sufficiently small, which means that the contractual wage $\mathrm{W}_{1}$ must be relatively high, and/or the productivity shock in the trial period must be sufficiently small. Only then, the expected product in the no signaling case, which is shown on the right hand side of

\footnotetext{
${ }^{15}$ A low-value worker will choose a positive number of overtime hours if: $\delta\left[\rho W_{2}+(1-\rho) W_{0}\right]-k \cdot \frac{v^{\alpha}}{\theta_{L}^{\beta}}>\delta W_{0}$.
} 
equation (15), is smaller or equal to the net income received in the signaling case. How big the contractual wage or how small the productivity shock has to be, depends on the cost elasticity of the quality, and on the ratio of the values of low- and high- quality workers, which corresponds to the ratio of the signaling costs of $\mathrm{H}$ and $\mathrm{L}$. The outcome that a high-value worker might be worse off in the presence of signaling than in the no signaling case seems to be paradoxical, since he chooses himself to perform the signaling activity. The reason is that, in the separating equilibrium, firm's beliefs are such that their strategy from the no-signaling situation, and hence the expected wage $\rho \cdot W_{2}+(1-\rho) \cdot W_{0}$, is no longer available. If he chooses a low level of overtime, he is thought to be of low-value type and runs the risk of being laid off after the trial period.

\subsection{Refinements}

The results above demonstrated that the outcome of a separating or pooling equilibrium depends on the firm's beliefs about the worker's value dependent on the observed level of overtime. It was shown that the assumption of a negative relationship between the worker's value and his cost of working overtime is necessary, but not sufficient to ensure that low-value workers are deterred from pretending to be of a high-value type. Cho and Kreps (1987) show that in a simple signaling model with only two types of workers, pooling equilibria as well as Pareto dominated separating equilibria can be ruled out. Therefore, by using their intuitive criterion, the best separating equilibrium can be predicted as unique outcome, i.e. only the equilibrium with the minimum cut-off level of overtime hours survives. However, in a more complex framework, e.g. with continuous types of workers, the outcome is not clear. Therefore, which one of these equilibria may be sustained and to which extent overinvestment in overtime exists, rests on the model parameters, and therefore remains an empirical matter.

The simple theoretical framework above might be extended in many ways. First of all, one could explicitly model two- or multidimensional asymmetric information in order to distinguish precisely between different worker attributes. Therefore, one could set up a model, in which workers are differentiated not only with respect to their overall value to the firm, but distinguish between their productivity, disutility of work, and any constraints which they face. As Streb (2002) did in his education signaling model of two-dimensional asymmetric information, one could investigate the impact of the heterogeneity of the single attributes on the equilibrium outcome. Another extension to the model is to introduce employer learning. Altonji and Pierret (1997) use an education signaling model in which firm's beliefs are constantly revised, as soon as additional information becomes available. They show that with increasing employer learning, earnings become more 
dependent on the true productivity and less dependent on the signal. In the overtime signaling context, employer learning yields the testable prediction that the return to overtime should decline with experience, and that the signaling component of overtime must be small, if employers learn quickly. Furthermore, one might additionally assume that the productivity of a worker depends on the quality of the match between job requirements and the ability of the worker (Belman and Heywood, 1997). Jovanovic (1979) links employer learning and matching in his model, where the quality of the match is only known over time. In addition, external signaling would be a promising extension. Gibbons and Katz (1991) assume that retentions and layoffs serve as a signal to the outside market. The promotion of a worker signals that the worker is valuable, which induces competing firms to make wage offers. Lastly, one might apply a tournament framework (Lazear, 1981) to model overtime hours and their rewards, when the number of payoffs is limited. In such a tournament type model, the monetary rewards are usually fixed in advance, and workers are not necessarily remunerated according to their expected product. Furthermore, in tournaments, the relative performance matters, regardless of the absolute output of the worker. Consequently, one might employ overtime hours relative to others as a signal. Moreover, the overtime signaling model is closely related to optimal incentive contracts, when workers care about their future earnings. Gibbons and Murphy (1992) show that in the presence of high career concerns, i.e. implicit incentives, optimal explicit incentives can be adjusted downward by lowering the wage. Whereas output is observable in their model, the worker's action to increase output is not observable. ${ }^{16}$ As has been shown, a number of interesting extensions might be included in the model and their outcomes investigated. However, we tried to keep the model as simple as possible, and included the minimum of features which allow us to test empirically whether overtime serves as a signaling device.

\subsection{From Theory to Empirical Testing}

The simple framework above has shown that overtime might serve as a signaling device if certain conditions are met. The most important prerequisite for the overtime signal to function is the singlecrossing property, which is necessary but not sufficient to sort high-value from low-value workers. Whether workers of different value types can in fact be distinguished, rests upon the beliefs of the firm, which can deter low-quality workers from mimicking as high-quality workers by choosing the right retention and layoff strategies with appropriate overtime cut-off levels. The overtime signaling model provides a number of predictions on the likelihood of the separating or pooling equilibrium

\footnotetext{
${ }^{16}$ This theory might therefore not be suitable to reproduce "display overtime", but it might be a very attractive approach to model unpaid hours which are performed in absence of the supervisor, such as taking work home at nights and on weekends.
} 
to persist. However, many of the model parameters, which affect the probability of a separating equilibrium to hold, such as the cost elasticities with respect to ability and overtime, and the wage differential between high- and low-value workers, have the same effects on the existence of a pooling equilibrium, where all workers pool at high overtime levels. Therefore, it might be difficult to empirically test one or the other type of equilibrium. An unequivocal implication which can be derived from the model is that a lower wage differential increases the probability of pooling at a zero overtime level, as low payoffs make overtime too costly even for high-value workers. This implication might be empirically tested by investigating the relationship between wage dispersion and overtime work. Indirect evidence has been found by Bell and Freeman (2001) who investigate the relationship between wage inequality and the supply of total working hours by comparing Germany and the U.S.. They conclude that the larger number of hours worked by Americans can be explained by responses to the greater earnings inequality. In terms of the overtime signaling theory, Germany could hence be interpreted as being in a low level pooling equilibrium, whereas the equilibrium in the U.S. might be pooling at a high level or separating high-value and low-value workers.

Another implication of the overtime signaling model is that a high retention probability makes pooling equilibria more likely to hold, regardless of the overtime level at which high-value and lowvalue workers pool. ${ }^{17}$ Within the above model, this implies that pooling is more likely for a low trial period wage, and for a positive shock in the trial period, as the retention probability $\rho=\operatorname{Pr}\left(\bar{\theta} \geq W_{1}\right)$. However, one might also take other determinants of retention into account, which are not included as variables in the model. For instance, employment protection is likely to lead to a higher retention probability and would not lead high-value and low-value workers to separate. The same variables, high retention probability, a low trial period wage, and a positive shock in the trial period, increase the welfare gain of high-value workers in the absence of signaling. For instance, in the presence of employment protection, a high-value worker does not gain much from signaling his high value to the firm and is likely to be better off without signaling. This could be tested by examining whether overtime workers are more likely to be overemployed, i.e. work more actual hours than desired, in the presence of employment protection. Lastly, high-value workers are likely to be better off if the value difference between the worker types is small, i.e. if the ratio of their signaling cost is almost zero. Yet, all the testing strategies above have the common problem that is it difficult to distinguish between high-and low-value workers in the data. It is difficult to determine

\footnotetext{
${ }^{17}$ This follows from the conditions for a pooling equilibrium, which are shown in Section 4.3.3.
} 
the value of a worker to his firm, as the true value is not observable, hardly possible to measure and unlikely to be available in datasets.

However, one testable prediction is the implication of the model that in a separating equilibrium, overtime signaling leads to payoffs in the form of higher retention probabilities and higher wages. Therefore, one might investigate whether firms take unpaid overtime in fact as a signal to derive a worker's value, and pay higher wages to workers with overtime hours. Yet, this implication of the overtime signaling model is shared with other theories. The human capital model and the theory of deferred compensation both predict a positive relationship between hours and current or future earnings. According to these theories, working hours are, however, used productively, either to increase the worker's stock of human capital or output. Hence, an empirical test might aim at separating the two effects, the signaling and the productive component, of overtime. The finding of a signaling component of extra hours would yield empirical evidence for the overtime signaling theory.

\section{Empirical Testing}

\subsection{Identification Strategy}

\subsubsection{Earnings Effects of Unpaid Overtime}

The objective of the empirical section is to examine whether unpaid overtime is in fact taken as a signal by firms to evaluate a worker's value. Firms might sort workers on the basis of extra hours, and pursue human resource strategies or wage policies dependent on the overtime level. The focus of this empirical study is to analyze whether unpaid overtime raises earnings of overtime workers due to this sorting effect. Data from the SOEP shows that male white-collar workers in West Germany earned on average 3,940€ per month in 2004, whereas the average was 4,508€ for those who worked unpaid overtime. Table 1 presents estimates of an earnings regression, which reveal that workers with unpaid overtime earn indeed more than non-overtime workers, even if individual and firm characteristics are controlled for. Workers with unpaid overtime have on average about $15 \%$ higher monthly earnings. Yet, a positive association between unpaid overtime and current or future wages is also consistent with the human capital model or the theory of deferred compensation. These models have the same implications as the overtime signaling theory, as overtime workers will yield a higher output and receive higher wages. However, while working hours are used to raise individual productivity in the human capital theory and to increase overall 
output in the theory of deferred compensation, the signaling framework uses overtime merely to identify valuable workers. The question is therefore whether the effect of overtime on wages only reflects a rise in output during an overtime hour, or whether it reflects, at least in part, unobserved value of the worker. These effects could, in theory, be separated by measuring a worker's overall output with and without working overtime hours separately. Evidence for the human capital or deferred compensation theory could be found if the product with overtime work was higher. This testing strategy is however difficult to implement. Another way of separating productive and signaling effects is to find workers of equal output and randomly assign overtime to them. According to the signaling hypothesis, the overtime worker should receive higher earnings. Therefore, support for overtime signaling would be a positive price of the signal in equilibrium, even when the signal itself has no impact on productive output.

In addition to the problem of discriminating competing theories, an endogeneity problem arises in the earnings estimates presented in Table 1 from workers self-selecting into jobs with unpaid overtime. Workers with unpaid extra hours might earn more than non-overtime workers regardless of working overtime. Therefore, it is impossible to infer any causal effect of overtime on the earnings of a worker with unpaid extra hours from simple earnings comparisons.

Table 1: $\quad$ Pooled OLS Wage Regression for West German Full-time Male Employees

\begin{tabular}{|c|c|c|}
\hline $\begin{array}{l}\text { Dependent variable: } \\
\text { Log monthly earnings }\end{array}$ & Coefficient & Standard Error \\
\hline Unpaid overtime & 0.149 & $(0.007)^{* *}$ \\
\hline Contractual Hours & 0.012 & $(0.002)^{* *}$ \\
\hline Age & 0.002 & $(0.001)$ \\
\hline Married & 0.055 & $(0.007)^{* *}$ \\
\hline Education in years & 0.018 & $(0.010)$ \\
\hline Education in years ${ }^{2}$ & 0.001 & $(0.000)^{*}$ \\
\hline Tenure & 0.009 & $(0.001)^{* *}$ \\
\hline Tenure $^{2}$ & 0.000 & $(0.000)^{* *}$ \\
\hline Experience & 0.029 & $(0.001)^{* *}$ \\
\hline Experience $^{2}$ & -0.001 & $(0.000)^{* *}$ \\
\hline Public Sector & -0.066 & $(0.009) * *$ \\
\hline Intercept & 6.244 & $(0.094)^{* *}$ \\
\hline Observations & 11,032 & \\
\hline $\begin{array}{ll}\text { Source: } & \text { SOEP, } 1993-2004 \\
\text { Note: } & \text { Industry, region, } \\
& \text { Adjusted R-Squa } \\
& * \text { significant at 50 }\end{array}$ & $\begin{array}{l}\text { rm size, and y } \\
57, \text { Prob }>\text { F } \\
\text { significant at } 1\end{array}$ & $\begin{array}{l}\text { dummies included } \\
.0000\end{array}$ \\
\hline
\end{tabular}




\subsubsection{A Quasi-Experiment with Unpaid Overtime}

In order to discriminate the signaling implication against predictions of the human capital theory and the theory of deferred compensation, we need to investigate whether unpaid overtime hours are in fact used to identify high-quality workers. This requires a random assignment of the signal to workers, which have otherwise identical expected productivity. To achieve this, we exploit variations in collectively bargained hours between industries as well as changes in contractual hours within industries over time. ${ }^{18}$ Differences in the standard workweek result in differences in the overtime threshold, faced by workers if they wish to supply overtime. For instance, a worker in the transport industry, which agreed to 39 hours, has to work 40 weekly hours to perform one overtime hour, whereas a worker in manufacturing with the same actual workweek, performs three overtime hours, if the manufacturing industry agreed to a standard of 37 weekly hours. Consequently, workers who would work overtime in some industries, would not work overtime in others. Therefore, we propose a quasi-experiment, in which we assume random assignment of the overtime signal to workers with the same actual working hours across different industries. A pure signaling effect may be identified by determining who these „marginal“ workers, i.e. the workers with overtime in one but not in another industry, are. The comparison of these workers' earnings might give information on whether overtime has a signaling value. Actual working hours might increase both, the overall output of the worker, and the signaling value of the worker. Whereas human capital theory predicts that all workers in the same industry with the same actual working hours should receive the same earnings later on, according to the overtime signaling theory, workers with marginal actual hours are predicted to earn more, when they work overtime. Figure 3 depicts the distribution of actual and contractual working hours for male full-time employees in West Germany to illustrate the identification strategy. If two workers are observed to work the identical number of actual hours, it may be the case that they differ in their agreed working time. While worker A might have a standard workweek of 39 hours, the agreed working time might be only 38.5 hours for worker B. Consequently, worker B performs overtime, whereas worker A does not, although he works the same weekly hours. The situation that only some of the workers provide unpaid overtime can be interpreted as separating market equilibrium, in which workers obtain the signal if the payoff is higher than the cost, and do not obtain it otherwise. Consequently, employers presume a high worker value, and therefore pay a higher wage, if they observe unpaid overtime. The prerequisite for unpaid extra hours to serve as a signal in equilibrium is that the cost of working overtime is negatively related to the worker's value.

\footnotetext{
${ }^{18}$ This identification strategy is similar to the one used by Tyler, Murnane, and Willett (2000) in the education signaling context.
} 
Figure 3: $\quad$ Hours Distribution of West German Full-time Male Employees (2004)

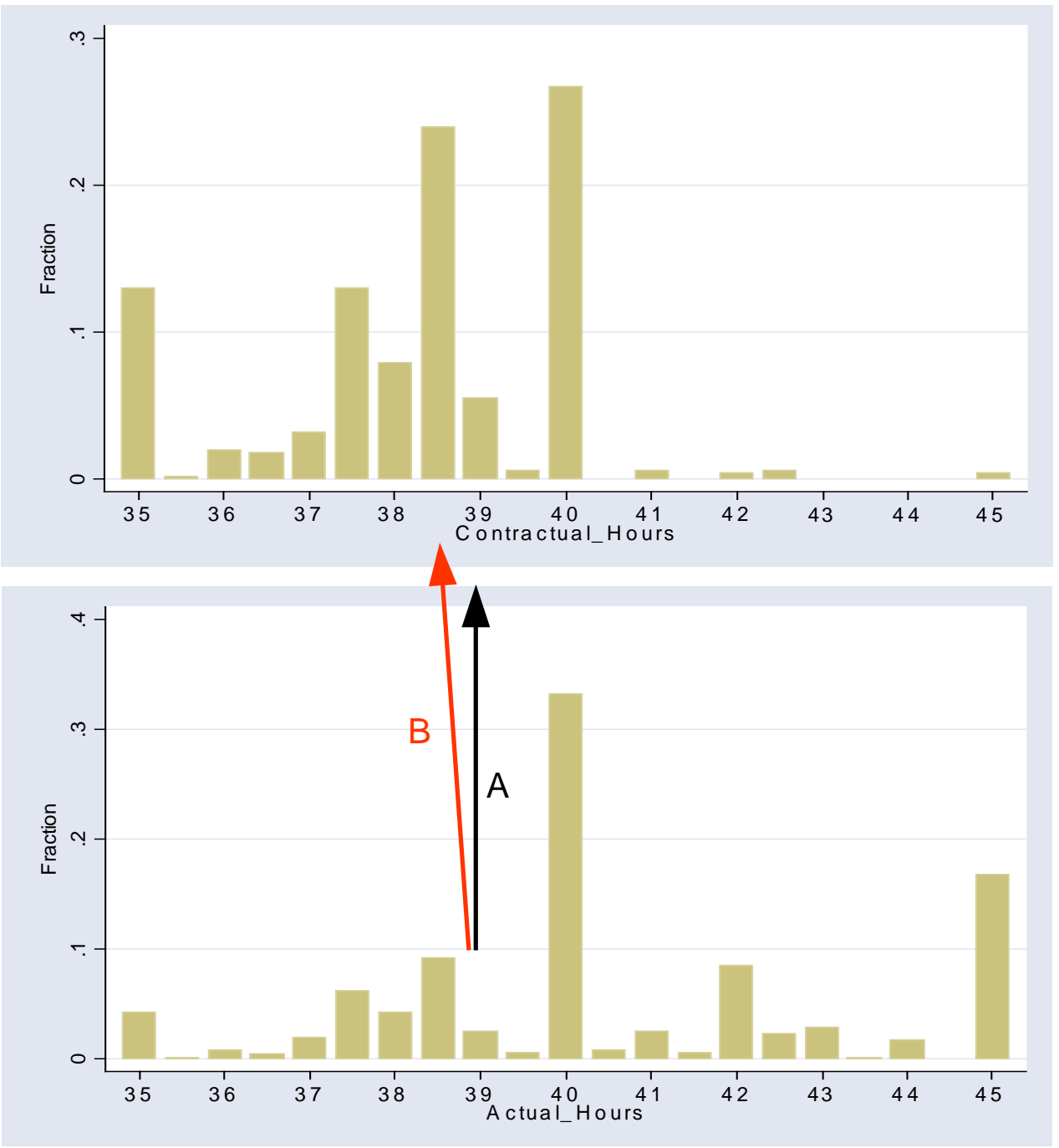

Source: SOEP, 2004

Note: Workers with contractual or actual hours greater than 45 are not depicted in the graph.

In the following, we focus on the relationship between current unpaid hours and current wages in order to separate the signaling value from effects which might arise from deferred compensation. However, we will investigate the link between current unpaid overtime and future earnings in an extension of the model.

\subsubsection{Econometric Strategy}

To identify overtime signaling effects we use a difference-in-differences approach, where the treatment is overtime and the treatment group are "marginal" workers, i.e. those who would work overtime in one industry, but not in another. The control group are workers with average working time above the standard hours of all considered industries. Therefore, these workers provide overtime regardless of the industry which they are working in. Figure 4 shows the research design of the overtime treatment. To take up the example of the workers with 39 weekly hours, we may assume an overtime threshold of 39 weekly hours, i.e. some industries have collectively agreed on 
39 or more hours (high, H), and some others below (low, L). Consequently, workers with 39 hours are part of the treatment group, as they would perform overtime in industries with a low standard workweek, but not in industries with a high level of standard hours. We have seven quasiexperiments that are denoted by the particular overtime threshold, which range from 39 to 45 weekly hours. The outcome measure is mean earnings of the four different worker groups, $\bar{Y}$, which according to the signaling theory, depend on whether the worker has obtained the overtime signal or not. The difference between workers of the treatment group in different industries is the earnings differential of overtime and no overtime workers who have the same amount of weekly hours $\left(\Delta \overline{\mathrm{Y}}^{\mathrm{T}}\right)$. The difference between workers of the control group in different industries is the earnings differential of "non-marginal" overtime workers with the same actual hours across industries $\left(\Delta \overline{\mathrm{Y}}^{\mathrm{C}}\right)$. As a result, industry differentials can be netted out by differencing $\left(\Delta \overline{\mathrm{Y}}^{\mathrm{T}}\right)$ $\left(\Delta \overline{\mathrm{Y}}^{\mathrm{C}}\right)$, which leads to the difference-in-differences estimate.

Figure 4: Research Design: Difference-in-Differences

\begin{tabular}{|c|c|c|}
\cline { 2 - 3 } \multicolumn{1}{c|}{} & \multicolumn{2}{c|}{ Contractual hours agreement in the industry } \\
\hline Actual working hours & Low (L) & High (H) \\
\hline Low & overtime & no overtime \\
\hline High & overtime & overtime \\
\hline
\end{tabular}

Outcome Variable:

\begin{tabular}{|l|c|c|}
\hline & \multicolumn{2}{|c|}{ Earnings (Y) } \\
\hline Treatment group & $\overline{\mathrm{Y}}_{\mathrm{L}}^{\mathrm{T}}$ & $\overline{\mathrm{Y}}_{\mathrm{H}}^{\mathrm{T}}$ \\
\hline Control group & $\overline{\mathrm{Y}}_{\mathrm{L}}^{\mathrm{C}}$ & $\overline{\mathrm{Y}}_{\mathrm{H}}^{\mathrm{C}}$ \\
\hline
\end{tabular}

The treatment effect is therefore equal to $\left(\Delta \overline{\mathrm{Y}}^{\mathrm{T}}\right)-\left(\Delta \overline{\mathrm{Y}}^{\mathrm{C}}\right)=\left(\overline{\mathrm{Y}}_{\mathrm{L}}^{\mathrm{T}}-\overline{\mathrm{Y}}_{\mathrm{H}}^{\mathrm{T}}\right)-\left(\overline{\mathrm{Y}}_{\mathrm{L}}^{\mathrm{C}}-\overline{\mathrm{Y}}_{\mathrm{H}}^{\mathrm{C}}\right)$. The same result is obtained by using a regression framework, which allows the inclusion of additional control variables. Therefore, earnings are estimated with a difference-in-differences estimator of the following structure: ${ }^{19}$

$$
\ln Y_{i, t}^{Z}=\alpha_{i}+\beta^{\prime} T_{i, t}^{Z}+\delta^{\prime} T_{i, t}^{Z} \cdot L_{i, t}^{Z}+\gamma^{\prime} L_{i, t}^{Z}+\eta^{\prime} X_{i, t}+\varepsilon_{i, t},
$$

where $\ln Y_{i, t}$ is the $\log$ of monthly earnings of the individual $i$ at time $t$. $T_{i t}$ is a dummy variable which equals one if the worker is in the treatment group, i.e. works "marginal" hours, and zero if

\footnotetext{
${ }^{19}$ See Wooldridge (2002).
} 
the worker is in the control group. $L_{i t}$ is a dummy variable which indicates that the industry has "low" standard hours, i.e. an agreed workweek of below the overtime threshold. The interaction term $T_{i t} \cdot L_{i t}$ is the treatment effect, and $X_{i t}$ are worker and firm characteristics. $\alpha_{i}$ is the individual specific effect, $\beta, \delta, \gamma$, and $\eta$ are parameters to be estimated, and $\varepsilon_{i t}$ is an error term which is distributed with mean 0 and variance $\sigma_{\varepsilon}^{2} . Z$ denotes the overtime threshold of the quasi-experiment: $Z=39, . .45$. The crucial parameter is the coefficient on the interaction term, $\delta$, since this gives the

true effect of the treatment: $\hat{\delta}_{D D}=\bar{Y}_{L}^{T}-\bar{Y}_{H}^{T}-\left(\bar{Y}_{L}^{C}-\bar{Y}_{H}^{C}\right)$. The parameter $\gamma$ accounts for average permanent differences between workers with different contracted hours, and $\beta$ captures the treatment group specific effects. The identification of the difference-in-differences estimator requires that the differences in overtime thresholds across industries and contracts generate exogenous variation in the overtime signal. Hence, the interaction and the error terms are required to be independent: $\operatorname{cov}\left(\varepsilon_{i, t}, T_{i, t} \cdot L_{i, t}\right)=0 .^{20}$

In addition to the worker and firm characteristics, we can control for individual heterogeneity by taking advantage of the panel structure of the dataset. Cross-sectional analyses might be biased by unobserved heterogeneity, which can be partially solved by differencing out individual fixed effects. In addition to a pooled OLS model, we will hence estimate the difference-in-differences by a random effects model, which assumes the individual specific effect $\alpha_{i}$ to differ across individuals but to be constant over time. Furthermore, $\alpha_{i}$ is assumed to be randomly distributed across individuals and not to be correlated with the set of explanatory variables. To allow for correlation between $\alpha_{i}$ with the explanatory variables, a fixed effects model will be estimated.

\subsubsection{Treatment and Control Group}

The treatment group includes all workers with actual working hours identical to the overtime threshold. However, the treatment, which is the assignment of the unpaid overtime signal, is only effective for those whose contracted hours are below the overtime threshold and whose extra hours are not compensated. In contrast, workers whose contractual hours equal the overtime threshold or who work other compensation forms of overtime, are considered to be non-treated. Hence, we want to contrast the value of one unpaid overtime hour with a working hour of any other compensation form. In order to include these other types of overtime workers in the non-treated part of the treatment group we have to recode overtime which is compensated with a wage payment or with

\footnotetext{
${ }^{20}$ This assumption is also known as the parallel-trend assumption (Meyer, 1995).
} 
time-off to obtain a true picture of the relation between monthly earnings and actual hours worked. ${ }^{21}$ Hence, we presume that both employers and workers have agreed on any paid or leisure compensated extra hour, and consider overtime agreements as an extension to the standard contract. We therefore add paid overtime hours to the agreed standard hours, which implies that the contracted working time of paid overtime workers equals actual working time. Furthermore, since leisure compensated extra hours are supposed to be taken as time-off at a later point in time, we do not count them as definite overtime hours. Therefore, we subtract leisure compensated overtime from actual working hours so that the actual working time of leisure compensated overtime workers equals contracted working time. This implies a strong test of the signaling value, since doing so eventually leads to the earnings comparison of workers with one unpaid hour with workers who might possibly perform several leisure compensated overtime hours a week. We could easily relax this assumption and consider hours in working time accounts, like paid overtime, as part of the contracted working hours, which we will do in the robustness check section. ${ }^{22}$ For partially paid, partially leisure compensated overtime hours, we apply a mixed procedure. We consider $40 \%$ of these overtime hours to be paid and add them to the contractual time, whereas we subtract the $60 \%$ of extra hours, which are supposed to be taken as time-off, from actual hours. ${ }^{23}$ Hence, the generated contractual hours equal the generated actual hours for this worker group. An alternative way of forming the non-treated part of the treatment group would be to consider only workers without any overtime hours. However, this would mean to exclude all other workers from the study, which might be a problem. The comparison of workers with unpaid overtime with workers without any overtime hours is likely to reveal huge earnings differences, which however may probably not measure the signaling effect of unpaid hours, but rather the stark discrepancies in unobserved characteristics between these worker groups. Reducing the non-treated group to no overtime workers would therefore restrict any conclusion on the productive value and the signaling value of unpaid overtime substantially. Still, we will try this alternative approach for comparison.

To form the comparison group we use all individuals with unpaid overtime and actual hours greater than the overtime threshold. Therefore, we grouped all unpaid overtime workers of higher actual hours together. The reason is that restricting the comparison group to one level of actual working hours would involve an arbitrary decision on which number of actual hours should be used. Furthermore, only using unpaid overtime workers with one exact level of actual working hours

\footnotetext{
${ }^{21}$ Unfortunately, data on monthly earnings excluding overtime pay, if there is any, is not available.

${ }^{22}$ Furthermore, there are strong guesses that not all of the leisure compensated overtime is indeed compensated with time-off later on, and turn out to be unpaid hours. However, there is no empirical evidence on this issue.

${ }^{23}$ This is consistent with information from the SOEP since 2002 , as on average around $40 \%$ of the partly paid, partly leisure-compensated overtime hours were paid.
} 
would shrink the comparison group considerably. While some of the workers in the control group belong to an industry with low standard hours, i.e. have low hours contracts, others have contracts with high working hours. However, all of them perform unpaid overtime.

\subsection{Data}

The data used in this study were made available by the German Socio-Economic Panel Study (SOEP) at the German Institute for Economic Research (DIW) in Berlin. ${ }^{24}$ We use information from 1993 to 2004 for male and female workers in East and West Germany aged between 20 and 60. Workers older than 60 were dropped because their contracts often specify a lower standard workweek due to (early) retirement plans. Furthermore, we exclude foreigners, civil servants, selfemployed persons, and workers employed in the agricultural sector. To deal with a homogeneous group with respect to working hours, we only use full-time employees. Although East Germans took part in the survey since 1991, we only use the waves from 1993 on, since some variables are not available for the East sample before that year. We dropped workers with more than 45 contractual hours in order to exclude obvious outliers. Furthermore, respondents with missing information on working hours or on other variables included in the estimates were not included in the sample. We include respondents who participated in at least two waves of the survey in order to be able to control for individual unobserved heterogeneity by using panel estimators. In total, the sub-sample consists of about 27,300 person-year-observations, of which 16,800 are from West Germany, and 10,500 are from East Germany.

Our dependent variable is monthly labor income, which reflects the true value of the worker to the firm. The SOEP provides information on monthly gross earnings including overtime payments. Information on extra payments, such as Christmas bonus, holiday pay, and income from profit sharing, is not included in this analysis, since this information is only provided in the subsequent year. Dropping persons without this information from the sample would lead to a substantial reduction in the number of observations. ${ }^{25}$ The information on working hours provided by the SOEP is central to our study to construct the quasi-experiment. Detailed information is available on overtime hours worked during the last month before the survey, and can be combined with information on the compensation form to obtain the amount of unpaid overtime hours per week. ${ }^{26}$

\footnotetext{
${ }^{24}$ For more details on the SOEP, see Haisken-DeNew and Frick (2003).

${ }^{25}$ However, extra payments have been shown to become increasingly important in recent years (Pierce, 1999).

Therefore, we conducted additional estimations with earnings including extra payments for the smaller sample, but did not discover any large changes in the main findings.

${ }^{26}$ The original questions in the SOEP read as follows: "Do you work overtime?" [Yes/No/Not applicable because I am self-employed]; "If you work overtime, is the work paid, compensated with time-off, or not compensated at all?"
} 
Furthermore, overtime hours can be calculated by differencing actual and contractual hours usually worked. Since the distinction between actual and contractual hours is crucial to our study, we use the latter method together with the information on compensation of extra hours to determine the amount of unpaid overtime. To control for heterogeneity between workers, we add a number of worker and firm characteristics which might potentially affect labor income. Therefore, we include control variables for occupations, blue-collar and white-collar workers, firm size, whether a person works in the public sector, and whether he holds a temporary or a permanent job. Further socioeconomic variables are age, sex, marital status, education, work experience, and tenure. All regressions additionally include industry, region, and year dummies as controls. Since the Chow test for structural change (Greene, 2000) revealed that the regression coefficients are significantly different in the subsets of the data, all regressions are run separately for East and West German workers, but for female and male workers together to ensure a sufficient number of observations in the particular treatment and comparison groups. Summary statistics of the variables used in the difference-in-differences estimates are provided in Table A1 in the Appendix.

\subsection{Results}

\subsection{1. "Raw" Estimates}

Before we conduct the regressions with the control variables, we consider the estimate of the "raw" signaling effect of unpaid overtime with the example of an overtime threshold of 40 weekly hours. Table 2 shows the difference-in-differences estimate for West German workers. The industry differential between workers within the treatment group shows that workers with unpaid overtime have on average higher earnings than workers with the same amount of actual hours but without unpaid overtime. The differential within the control group also shows slightly higher earnings for workers in the industry or in the contract with lower specified hours, although both groups work unpaid overtime. Netting out the industry differentials leads to a positive difference-in-differences estimate, suggesting that for workers who are on the 40 hours margin of working unpaid overtime, the signaling value of unpaid work increases earnings by $12 \%$. However, as these earnings differentials are likely to be also influenced by worker and firm characteristics other than unpaid hours, the following estimates include the full set of control variables.

[Compensated with time-off/Partly paid, partly compensated with time-off/Paid/Not compensated at all]; "How was your situation with regards to overtime last month? Did you work overtime? If yes, how many hours?" [Yes, hours/No]. 
Table 2: Raw DD Estimate of the Impact of Unpaid Overtime on Earnings for West German Workers (Overtime Threshold: 40 Hours per Week)

\begin{tabular}{|l|c|c|c|}
\cline { 2 - 3 } \multicolumn{1}{c|}{} & \multicolumn{2}{c|}{ Contractual hours in the industry } & \multicolumn{1}{c|}{} \\
\hline Actual working hours & Low $(<40)$ & High $(\geq 40)$ & Low-high-contrast \\
\hline Low (=40): Treatment Group & $\begin{array}{c}2894.49 \\
(82.80)\end{array}$ & $\begin{array}{c}2481.82 \\
(24.22)\end{array}$ & 412.67 \\
\hline High ( $>40)$ : Control Group & $\begin{array}{c}3788.32 \\
(49.77)\end{array}$ & $\begin{array}{c}3670.63 \\
(65.83)\end{array}$ & 117.69 \\
\hline Difference-in-Differences & \multicolumn{3}{c}{$\begin{array}{c}294.98^{*} \\
(125.25)\end{array}$} \\
\hline
\end{tabular}

Source: SOEP, 1993-2004

Note: Standard errors are in parenthesis, * significant at the $5 \%$ level

\subsubsection{Difference-in-Difference Estimates}

The fully specified difference-in-differences estimates using a pooled OLS, a random effects and a fixed effects model are displayed in Table 3 for different levels of overtime thresholds. ${ }^{27}$ For the West German sample, the difference-in-differences estimate is significantly positive for unpaid overtime at the 40 hours margin, but negative at the 43 hours margin in the pooled OLS estimation. A negative signaling value is also found for East German workers who perform unpaid overtime at the 42 hours threshold. However, the inclusion of worker and firm characteristics as control variables is unlikely to be sufficient, since unobserved effects might drive the results. Therefore, panel estimators are used to control for person-specific unobserved heterogeneity. While the random effects specification does not reveal any statistically significant results, some of the fixed effects estimates are highly significant. For the West German sample, the positive effect of unpaid hours at the 40 hours threshold disappears, when unobserved heterogeneity is controlled for. However, by eliminating individual fixed effects, the formerly negative effect turns out to be significantly positive and implies an increase in earnings of about $10 \%$. An even stronger result is found for unpaid overtime at the 44 hours threshold. The positive and highly significant differencein-differences estimate suggests that working the $44^{\text {th }}$ hour as unpaid overtime is associated with $17 \%$ higher earnings. This result is strongly in favor of the signaling hypothesis. Without any signaling value, workers with the same actual hours should achieve the same output or firm-specific human capital, and therefore receive similar wages. The positive differential indicates that unpaid overtime has a signaling component.

The contrary seems to be true for East German workers, for whom only the difference-indifferences estimate at the 45 hours threshold is significant, but negatively associated with earnings.

\footnotetext{
${ }^{27}$ See Table A2 in the Appendix for the pooled OLS, the random effects, and the fixed effects estimates of all control variables.
} 
For unpaid overtime workers with 45 actual hours, the signaling value of unpaid work leads to a decrease in earnings by $22 \%$. Therefore, by working unpaid hours, East German workers may send a negative signal of their value to the firm. All of the applied models above have been tested against each other. The Breusch and Pagan multiplier test revealed for all estimates superiority of the random effects over the pooled OLS model, whereas the result of the Hausman specification test was in favor of the fixed effects model. To sum up, evidence can be found for a signaling component in overtime hours, which however does not necessarily signal a positive value of the worker. While for West German workers at the margin of 43 and 44 actual working hours, the signaling value of unpaid overtime is associated with an increase in earnings by $10 \%$ and $17 \%$, workers in East Germany at the 45 hours margin find the signaling value of unpaid overtime to lower their monthly income by $22 \%$.

Table 3: DD Estimates of the Impact of Unpaid Overtime on Earnings

\begin{tabular}{|c|c|c|c|c|c|c|}
\hline & \multicolumn{3}{|c|}{ West sample } & \multicolumn{3}{|c|}{ East sample } \\
\hline & $\begin{array}{c}\text { Pooled } \\
\text { OLS }\end{array}$ & $\begin{array}{l}\text { Random } \\
\text { Effects }\end{array}$ & $\begin{array}{c}\text { Fixed } \\
\text { Effects }\end{array}$ & $\begin{array}{c}\text { Pooled } \\
\text { OLS }\end{array}$ & $\begin{array}{c}\text { Random } \\
\text { Effects }\end{array}$ & $\begin{array}{c}\text { Fixed } \\
\text { Effects }\end{array}$ \\
\hline Overtime Threshold: 39 & $\begin{array}{l}0.082 \\
(1.83)\end{array}$ & $\begin{array}{l}0.058 \\
(1.85)\end{array}$ & $\begin{array}{l}0.040 \\
(1.25)\end{array}$ & - & - & - \\
\hline Observations & 6,555 & & & & & \\
\hline Overtime Threshold: 40 & $\begin{array}{c}0.050 \\
(2.39)^{*}\end{array}$ & $\begin{array}{l}0.029 \\
(1.78)\end{array}$ & $\begin{array}{l}0.018 \\
(1.04)\end{array}$ & $\begin{array}{l}-0.034 \\
(0.70)\end{array}$ & $\begin{array}{c}-0.024 \\
(0.65)\end{array}$ & $\begin{array}{l}-0.022 \\
(0.57)\end{array}$ \\
\hline Observations & 5,031 & & & 6,691 & & \\
\hline Overtime Threshold: 41 & $\begin{array}{l}-0.017 \\
(0.35)\end{array}$ & $\begin{array}{l}-0.020 \\
(0.54)\end{array}$ & $\begin{array}{l}-0.015 \\
(0.35)\end{array}$ & $\begin{array}{l}-0.054 \\
(0.78)\end{array}$ & $\begin{array}{l}-0.063 \\
(1.19)\end{array}$ & $\begin{array}{l}-0.081 \\
(1.40)\end{array}$ \\
\hline Observations & 2,431 & & & 1,943 & & \\
\hline Overtime Threshold: 42 & $\begin{array}{l}-0.052 \\
(1.18)\end{array}$ & $\begin{array}{l}0.013 \\
(0.35)\end{array}$ & $\begin{array}{l}0.051 \\
(1.19)\end{array}$ & $\begin{array}{c}-0.080 \\
(1.98)^{*}\end{array}$ & $\begin{array}{l}-0.025 \\
(0.78)\end{array}$ & $\begin{array}{l}-0.024 \\
(0.65)\end{array}$ \\
\hline Observations & 2,344 & & & 2,103 & & \\
\hline Overtime Threshold: 43 & $\begin{array}{c}-0.111 \\
(2.04)^{*}\end{array}$ & $\begin{array}{l}0.026 \\
(0.62)\end{array}$ & $\begin{array}{c}0.095 \\
(2.08)^{*}\end{array}$ & $\begin{array}{l}-0.085 \\
(1.59)\end{array}$ & $\begin{array}{l}-0.052 \\
(1.23)\end{array}$ & $\begin{array}{l}-0.073 \\
(1.46)\end{array}$ \\
\hline Observations & 1,980 & & & 1,623 & & \\
\hline Overtime Threshold: 44 & $\begin{array}{l}-0.044 \\
(0.61)\end{array}$ & $\begin{array}{l}0.091 \\
(1.76)\end{array}$ & $\begin{array}{c}0.155 \\
(2.76)^{* *}\end{array}$ & $\begin{array}{l}0.067 \\
(1.08)\end{array}$ & $\begin{array}{l}-0.019 \\
(0.40)\end{array}$ & $\begin{array}{l}-0.056 \\
(1.10)\end{array}$ \\
\hline Observations & 1,735 & & & 1,629 & & \\
\hline Overtime Threshold: 45 & $\begin{array}{l}-0.081 \\
(1.03)\end{array}$ & $\begin{array}{l}0.005 \\
(0.10)\end{array}$ & $\begin{array}{l}0.017 \\
(0.27)\end{array}$ & $\begin{array}{l}0.133 \\
(1.67)\end{array}$ & $\begin{array}{l}-0.043 \\
(0.67)\end{array}$ & $\begin{array}{c}-0.243 \\
(3.11)^{* *}\end{array}$ \\
\hline Observations & 1,883 & & & 1,582 & & \\
\hline
\end{tabular}

Source: SOEP, 1993-2004

Sample: German full-time employees, age 20-60

Note: The regression model is full-specified, independent variables include worker and firm characteristics as well as region and year dummies. Absolute value of $t$ statistics in parentheses, $*$ significant at $5 \% ; * *$ significant at $1 \%$. 


\subsection{Robustness Checks and Extensions}

\subsubsection{The Endogeneity of Contractual Hours}

The results of the difference-in-differences estimator of a strong positive signaling value of unpaid work at some overtime thresholds for West German workers, and of even stronger, though negative effects on earnings at the 45 hours margin for East Germans are quite striking. The more is it important to exclude any alternative explanations and to extend the analysis to test their robustness. The first and most important issue is the problem of a possible endogeneity bias. Workers might self-select into jobs with certain contractual hours, and may therefore directly influence their overtime threshold. ${ }^{28}$ Similarly, the collectively bargained hours level could be affected by endogenous determinants, and therefore systematically shift industry overtime thresholds. The marginal hours might therefore no longer be randomly assigned to workers in different industries or contracts, which leads variations in the overtime signal to be endogenous. Furthermore, the differences in overtime thresholds might influence individual behavior in a systematic way. A worker's decision on whether to supply hours at all and on the amount of supplied actual hours might be dependent on the contractual hours available to the worker. Therefore, unobserved characteristics might not be the same for workers in the treatment group and in the comparison group, or between the treated and the non-treated workers. In formal terms, this refers to the violation of the parallel-trend assumption, as the error term may be correlated with the other variables in equation (16), which might bias the results.

The least problematic source of endogenity bias can be resolved by the assumption that the level of standard hours in the particular industries themselves are exogenous. As argued by Hunt (1999), the collectively agreed working hours in Germany are agreed to several years in advance, and cannot be easily modified in response to unforeseen changes in the economy or other reasons. Another issue is that the participation decision might be influenced by available standard hours, as high contractual hours might deter some workers from entering the labor market which have only access to long hours contracts. However, as these workers are unlikely to be of a high value for their firms, this selection implies an overestimation of the mean earnings in the industries with high standard hours, and a resulting downward bias in the estimated signaling effect of unpaid overtime. However, participating workers might still self-select in industries, which meet best their desired working hours. By migrating to other industries, they might realize lower contractual working hours and therefore increase the probability of obtaining the unpaid overtime signal. This is a problem if high-

\footnotetext{
${ }^{28}$ Evidence on self-selection of workers into long-hours jobs in the U.K. is provided by Bell and Hart (2003) who, however, do not differentiate between paid and unpaid long hours.
} 
value workers migrate to industries with low contractual hours, since this leads to an upward bias in the estimated effect of unpaid overtime on earnings. Therefore, we examine patterns of job changers in our sample to investigate whether systematic changes can be found. Among the West German job changers who performed unpaid overtime in their new job, only $16 \%$ came from a job with higher contractual hours, whereas $27 \%$ even increased their standard hours in the new job, and $57 \%$ started in a new workplace at the same level of contractual hours as in the old job. In contrast, among the workers without unpaid overtime in the new job, $26 \%$ managed to reduce their contractual hours. The percentage of workers who had higher standard hours in the new job was the same as among overtime workers, and $47 \%$ restarted at the same contractual hours level as in the old workplace. The detailed mobility patterns of West German workers are displayed in Table 4.

\section{Table 4: Mobility Patterns of Job Changers (West German Workers)}

\begin{tabular}{lccccccccccc}
$\begin{array}{l}\text { Contractual } \\
\text { Hours Before } \\
\text { Job Change }\end{array}$ & 35 & 36 & 37 & 38 & 39 & 40 & 41 & 42 & 43 & 44 & 45 \\
\hline 35 & 0.0 & 0.0 & 0.0 & 0.0 & 0.0 & 100.0 & 0.0 & 0.0 & 0.0 & 0.0 & 0.0 \\
36 & 0.0 & 0.0 & 0.0 & 0.0 & 56.6 & 43.4 & 0.0 & 0.0 & 0.0 & 0.0 & 0.0 \\
37 & 0.0 & 7.1 & 81.4 & 1.7 & 3.4 & 6.4 & 0.0 & 0.0 & 0.0 & 0.0 & 0.0 \\
38 & 3.8 & 0.0 & 6.1 & 38.5 & 13.4 & 38.2 & 0.0 & 0.0 & 0.0 & 0.0 & 0.0 \\
39 & 0.0 & 1.6 & 0.0 & 18.3 & 42.9 & 37.2 & 0.0 & 0.0 & 0.0 & 0.0 & 0.0 \\
40 & 3.2 & 0.7 & 1.8 & 6.5 & 18.2 & 67.5 & 0.3 & 1.9 & 0.0 & 0.0 & 0.0 \\
42 & 0.0 & 0.0 & 0.0 & 0.0 & 28.4 & 0.0 & 0.0 & 71.6 & 0.0 & 0.0 & 0.0 \\
44 & 0.0 & 0.0 & 0.0 & 0.0 & 0.0 & 0.0 & 0.0 & 100.0 & 0.0 & 0.0 & 0.0 \\
45 & 0.0 & 0.0 & 0.0 & 0.0 & 0.0 & 64.6 & 0.0 & 0.0 & 35.4 & 0.0 & 0.0 \\
Total & 2.4 & 1.1 & 6.9 & 15.4 & 22.2 & 50.1 & 0.1 & 1.8 & 0.1 & 0.0 & 0.0 \\
Observations & 171 & & & & & & & & & & \\
\hline
\end{tabular}

\begin{tabular}{|c|c|c|c|c|c|c|c|c|c|c|c|}
\hline \multirow{2}{*}{$\begin{array}{l}\text { Contractual } \\
\text { Hours Before } \\
\text { Job Change }\end{array}$} & \multicolumn{11}{|c|}{ Contractual Hours After Job Change: } \\
\hline & 35 & 36 & 37 & 38 & 39 & 40 & 41 & 42 & 43 & 44 & 45 \\
\hline 35 & 36.1 & 0.6 & 10.8 & 12.2 & 7.7 & 32.8 & 0.0 & 0.0 & 0.0 & 0.0 & 0.0 \\
\hline 36 & 14.3 & 22.7 & 11.6 & 18.9 & 8.0 & 24.5 & 0.0 & 0.0 & 0.0 & 0.0 & 0.0 \\
\hline 37 & 3.8 & 6.0 & 10.3 & 27.5 & 23.3 & 24.9 & 0.0 & 0.0 & 0.0 & 0.0 & 4.2 \\
\hline 38 & 4.9 & 2.3 & 5.5 & 47.6 & 20.2 & 18.9 & 0.0 & 0.0 & 0.0 & 0.0 & 0.6 \\
\hline 39 & 1.5 & 1.5 & 2.4 & 15.5 & 55.5 & 17.3 & 3.5 & 0.1 & 2.1 & 0.6 & 0.1 \\
\hline 40 & 7.7 & 0.4 & 0.7 & 13.9 & 19.0 & 57.1 & 0.2 & 0.6 & 0.0 & 0.0 & 0.5 \\
\hline 41 & 23.5 & 0.0 & 0.0 & 32.7 & 0.0 & 37.8 & 6.0 & 0.0 & 0.0 & 0.0 & 0.0 \\
\hline 42 & 0.0 & 0.0 & 0.0 & 5.6 & 2.8 & 91.6 & 0.0 & 0.0 & 0.0 & 0.0 & 0.0 \\
\hline 43 & 0.0 & 0.0 & 0.0 & 32.4 & 0.0 & 64.1 & 0.0 & 3.5 & 0.0 & 0.0 & 0.0 \\
\hline 44 & 0.0 & 22.2 & 0.0 & 77.8 & 0.0 & 0.0 & 0.0 & 0.0 & 0.0 & 0.0 & 0.0 \\
\hline 45 & 0.0 & 3.7 & 0.0 & 87.9 & 0.0 & 0.9 & 0.0 & 4.5 & 0.0 & 0.0 & 2.9 \\
\hline Total & 6.8 & 2.5 & 4.0 & 23.6 & 30.4 & 29.7 & 1.3 & 0.2 & 0.7 & 0.2 & 0.5 \\
\hline Observations & 899 & & & & & & & & & & \\
\hline
\end{tabular}

Source: SOEP, 1993-2004

Sample: West German full-time employees, age 20-60

Note: Rows add up to $100 \%$. Data are weighted using cross-sectional sample weights. 
Systematic movement of unpaid overtime workers from contracts with a high level of hours to low level contracts would be visible by relatively more migration out of the lower left-hand cells, and relatively few changes out of the upper left-hand cells to the right. However, there is no evidence of such a systematic movement to jobs with lower contractual hours. Therefore, mobility patterns do not seem to cause an endogeneity problem. However, it might still be the case that the decision on the amount of supplied actual hours is systematically influenced by the prevailing overtime threshold. This is a problem if high-value workers just work slightly above the threshold. In this case the treatment group would be contaminated with high-value workers who eventually would supply more hours if the threshold was higher. Consequently, their value is higher than indicated by the unpaid overtime signal, and an upward bias arises.

\subsubsection{Variations in the Counterfactual}

As another check of robustness, we try variations in the treatment group. While treated workers are still unpaid overtime workers with hours on the margin, we change the group of non-treated workers to which the unpaid overtime workers are directly compared to. First, as the redefinition of contractual and actual hours of workers with any form of compensated overtime is somewhat arbitrary, we investigate whether changes in this redefinition affect our results. Therefore, in an additional estimation, we consider hours in working time accounts as part of the contracted working hours, and consequently treat leisure compensated extra hours in the same way as paid overtime. This means that contractual hours of all workers who work some form of compensated overtime are set equal to the actual hours (Treatment Group II). Second, one might argue that workers with some form of compensated overtime hours are not the adequate counterfactual. Whereas workers without any overtime can possibly decide to work unpaid hours, this is not the case for workers who already perform paid or leisure compensated extra hours, since the corresponding responses are mutually exclusive in the SOEP questionnaire. Therefore, to form Treatment Group III, we exclude other compensation forms of overtime, and consider only no overtime workers to be non-treated.

Results of the random effects and fixed effects difference-in-differences estimates are displayed in Table 5. With both alternative treatment groups, the random effects estimates now are significant for the West German sample, and show a positive signaling value of unpaid overtime hours on the margin. However, the Hausman test again reveals superiority of the fixed effects model. The fixed effects results are fairly similar to the estimates of the original specification. In the estimates with treatment group II, the unpaid hours at the overtime threshold of 43 hours are not significant any more, but the coefficient of the treatment effect at the 44 hours threshold for West German workers is almost identical to the one in the main part of the analysis. For East Germans, the negative 
signaling effect of unpaid overtime hours on the 45 hours margin persists, but is slightly smaller. In treatment group II, only no overtime workers are considered as the counterfactual. The fixed effects specification reveals a strong and positive signaling value for unpaid work on the 43 hours margin for West German workers, whereas there is no estimate at the 44 hours due to insufficient observations in the group of non-treated workers. The signaling value of working unpaid hours at the 43 hours margin is associated with an increase in earnings by almost $70 \%$. Therefore, excluding all compensated overtime hours from the analysis, and comparing the value of an unpaid overtime hour only to contractual hours seems to lead to an overestimation of the signaling effect. However, the signaling value is again negative, and even stronger than in the main part of the analysis, for unpaid extra hours worked by East Germans at the 45 hours threshold. To sum up, the variation in the counterfactual slightly changes some of the estimates, but the main results, the positive signaling value of unpaid work for West Germans at the 43 and 44 hours threshold, and the negative value at the 45 hours threshold for East German workers, seem to prevail.

Table 5: DD Estimates of the Impact of Unpaid Overtime and Variations in the Treatment Group

\begin{tabular}{|c|c|c|c|c|c|c|c|c|}
\hline & \multicolumn{4}{|c|}{ Treatment Group II } & \multicolumn{4}{|c|}{ Treatment Group III } \\
\hline & \multicolumn{2}{|c|}{ West } & \multicolumn{2}{|c|}{ East } & \multicolumn{2}{|c|}{ West } & \multicolumn{2}{|c|}{ East } \\
\hline & $\mathrm{RE}$ & $\mathrm{FE}$ & $\mathrm{RE}$ & $\mathrm{FE}$ & $\mathrm{RE}$ & $\mathrm{FE}$ & $\mathrm{RE}$ & $\mathrm{FE}$ \\
\hline Overtime Threshold: 39 & $\begin{array}{c}0.069 \\
(2.05)^{*}\end{array}$ & $\begin{array}{l}0.038 \\
(1.10)\end{array}$ & - & - & $\begin{array}{c}0.083 \\
(2.33)^{*}\end{array}$ & $\begin{array}{l}0.046 \\
(1.25)\end{array}$ & - & - \\
\hline Observations & 4,669 & & & & 3,225 & & & \\
\hline Overtime Threshold: 40 & $\begin{array}{c}0.038 \\
(2.53)^{*}\end{array}$ & $\begin{array}{l}0.024 \\
(1.54)\end{array}$ & $\begin{array}{c}-0.048 \\
(1.25)\end{array}$ & $\begin{array}{l}-0.054 \\
(1.35)\end{array}$ & $\begin{array}{c}0.057 \\
(2.92)^{* *}\end{array}$ & $\begin{array}{l}0.040 \\
(1.90)\end{array}$ & $\begin{array}{c}0.004 \\
(0.10)\end{array}$ & $\begin{array}{l}0.000 \\
(0.00)\end{array}$ \\
\hline Observations & 5,985 & & 5,069 & & 2,794 & & 2,901 & \\
\hline Overtime Threshold: 41 & $\begin{array}{l}-0.008 \\
(0.21)\end{array}$ & $\begin{array}{l}-0.025 \\
(0.59)\end{array}$ & $\begin{array}{c}-0.047 \\
(0.88)\end{array}$ & $\begin{array}{l}-0.088 \\
(1.43)\end{array}$ & $\begin{array}{l}-0.093 \\
(1.14)\end{array}$ & $\begin{array}{l}-0.115 \\
(0.98)\end{array}$ & $\begin{array}{c}-0.052 \\
(0.47)\end{array}$ & $\begin{array}{l}0.029 \\
(0.16)\end{array}$ \\
\hline Observations & 2,366 & & 1,844 & & 1,884 & & 1,499 & \\
\hline Overtime Threshold: 42 & $\begin{array}{l}0.036 \\
(1.09)\end{array}$ & $\begin{array}{l}0.059 \\
(1.65)\end{array}$ & $\begin{array}{l}0.014 \\
(0.46)\end{array}$ & $\begin{array}{l}0.024 \\
(0.73)\end{array}$ & $\begin{array}{l}0.074 \\
(0.81)\end{array}$ & - & $\begin{array}{c}-0.016 \\
(0.26)\end{array}$ & $\begin{array}{c}-0.010 \\
(0.11)\end{array}$ \\
\hline Observations & 2,958 & & 2,449 & & 1,822 & & 1,489 & \\
\hline Overtime Threshold: 43 & $\begin{array}{l}0.031 \\
(0.77)\end{array}$ & $\begin{array}{l}0.066 \\
(1.54)\end{array}$ & $\begin{array}{c}-0.043 \\
(1.09)\end{array}$ & $\begin{array}{l}-0.072 \\
(1.60)\end{array}$ & $\begin{array}{c}0.258 \\
(2.93)^{* *}\end{array}$ & $\begin{array}{c}1.525 \\
(5.97)^{* *}\end{array}$ & $\begin{array}{l}0.060 \\
(0.81)\end{array}$ & $\begin{array}{c}-0.004 \\
(0.04)\end{array}$ \\
\hline Observations & 2,222 & & 1,904 & & 1,658 & & 1,367 & \\
\hline Overtime Threshold: 44 & $\begin{array}{l}0.068 \\
(1.35)\end{array}$ & $\begin{array}{c}0.156 \\
(2.92)^{* *}\end{array}$ & $\begin{array}{l}0.004 \\
(0.09)\end{array}$ & $\begin{array}{l}-0.061 \\
(1.09)\end{array}$ & $\begin{array}{l}0.071 \\
(0.32)\end{array}$ & - & $\begin{array}{c}-0.048 \\
(0.52)\end{array}$ & $\begin{array}{c}-0.134 \\
(1.17)\end{array}$ \\
\hline Observations & 1,824 & & 1,571 & & 1,522 & & 1,276 & \\
\hline Overtime Threshold: 45 & $\begin{array}{l}0.030 \\
(0.53)\end{array}$ & $\begin{array}{l}0.071 \\
(1.19)\end{array}$ & $\begin{array}{c}-0.003 \\
(0.05)\end{array}$ & $\begin{array}{c}-0.208 \\
(2.89)^{* *}\end{array}$ & $\begin{array}{l}0.063 \\
(0.83)\end{array}$ & $\begin{array}{l}0.032 \\
(0.34)\end{array}$ & $\begin{array}{c}0.001 \\
(0.01)\end{array}$ & $\begin{array}{l}-0.294 \\
(2.27)^{*}\end{array}$ \\
\hline Observations & 2,876 & & 2,470 & & 1,462 & & 1,223 & \\
\hline
\end{tabular}

Source: SOEP, 1993-2004

Sample: German full-time employees, age 20-60

Note: The regression model is full-specified, independent variables include worker and firm characteristics as well as region and year dummies. Absolute value of $\mathrm{t}$ statistics in parentheses, ${ }^{*}$ significant at $5 \%$; ** significant at $1 \%$. 


\subsubsection{Future Earnings and Deferred Compensation}

To avoid underestimating the impact of unpaid overtime by measuring earnings too close to the receipt of the signal, we additionally estimate the effect of unpaid overtime on future earnings. This is relevant, since it might take a while until the signal is received by the employer and possibly reflected in the worker's earnings. A positive relationship between current overtime and future earnings was predicted by the overtime signaling model, but is also consistent with the theory of deferred compensation. To analyze future effects of marginal unpaid overtime hours we have to restrict the sample to job stayers or at least to firm stayers, as for firm changers these earnings arise in new workplaces, where previous overtime levels cannot be observed. Table 6 shows estimates of the unpaid overtime treatment on earnings in the subsequent period. ${ }^{29}$

Table 6: DD Estimates of the Impact of Unpaid Overtime on Future Earnings (Subsequent Year)

\begin{tabular}{|c|c|c|c|c|c|c|}
\hline & \multicolumn{3}{|c|}{ West sample } & \multicolumn{3}{|c|}{ East sample } \\
\hline & $\begin{array}{c}\text { Pooled } \\
\text { OLS }\end{array}$ & $\begin{array}{l}\text { Random } \\
\text { Effects }\end{array}$ & $\begin{array}{l}\text { Fixed } \\
\text { Effects }\end{array}$ & $\begin{array}{c}\text { Pooled } \\
\text { OLS }\end{array}$ & $\begin{array}{l}\text { Random } \\
\text { Effects }\end{array}$ & $\begin{array}{l}\text { Fixed } \\
\text { Effects }\end{array}$ \\
\hline Overtime Threshold: 39 & $\begin{array}{c}0.122 \\
(2.34)^{*}\end{array}$ & $\begin{array}{c}0.068 \\
(2.09)^{*}\end{array}$ & $\begin{array}{c}0.004 \\
(0.11)\end{array}$ & - & - & - \\
\hline Observations & 3,216 & & & & & \\
\hline Overtime Threshold: 40 & $\begin{array}{c}0.056 \\
(2.43)^{*}\end{array}$ & $\begin{array}{l}0.027 \\
(1.55)\end{array}$ & $\begin{array}{c}0.007 \\
(0.37)\end{array}$ & $\begin{array}{c}-0.011 \\
(0.17)\end{array}$ & $\begin{array}{l}-0.015 \\
(0.31)\end{array}$ & $\begin{array}{l}-0.037 \\
(0.74)\end{array}$ \\
\hline Observations & 3,928 & & & 3,351 & & \\
\hline Overtime Threshold: 41 & $\begin{array}{l}-0.005 \\
(0.08)\end{array}$ & $\begin{array}{l}0.015 \\
(0.34)\end{array}$ & $\begin{array}{c}-0.030 \\
(0.60)\end{array}$ & $\begin{array}{c}-0.107 \\
(1.32)\end{array}$ & $\begin{array}{l}-0.080 \\
(1.28)\end{array}$ & $\begin{array}{l}-0.080 \\
(1.08)\end{array}$ \\
\hline Observations & 1,537 & & & 1,235 & & \\
\hline Overtime Threshold: 42 & $\begin{array}{l}-0.082 \\
(1.63)\end{array}$ & $\begin{array}{l}-0.027 \\
(0.73)\end{array}$ & $\begin{array}{l}-0.010 \\
(0.24)\end{array}$ & $\begin{array}{c}-0.067 \\
(1.41)\end{array}$ & $\begin{array}{l}0.018 \\
(0.48)\end{array}$ & $\begin{array}{l}0.059 \\
(1.47)\end{array}$ \\
\hline Observations & 1,951 & & & 1,688 & & \\
\hline Overtime Threshold: 43 & $\begin{array}{l}-0.092 \\
(1.48)\end{array}$ & $\begin{array}{l}-0.015 \\
(0.33)\end{array}$ & $\begin{array}{l}-0.015 \\
(0.29)\end{array}$ & $\begin{array}{c}-0.102 \\
(1.73)\end{array}$ & $\begin{array}{l}-0.090 \\
(1.97)^{*}\end{array}$ & $\begin{array}{l}-0.070 \\
(1.32)\end{array}$ \\
\hline Observations & 1,455 & & & 1,275 & & \\
\hline Overtime Threshold: 44 & $\begin{array}{l}0.010 \\
(0.12)\end{array}$ & $\begin{array}{l}0.065 \\
(1.10)\end{array}$ & $\begin{array}{l}0.112 \\
(1.62)\end{array}$ & $\begin{array}{l}0.040 \\
(0.53)\end{array}$ & $\begin{array}{l}-0.003 \\
(0.06)\end{array}$ & $\begin{array}{l}0.007 \\
(0.09)\end{array}$ \\
\hline Observations & 1,185 & & & 1,062 & & \\
\hline Overtime Threshold: 45 & $\begin{array}{l}-0.044 \\
(0.52)\end{array}$ & $\begin{array}{l}0.025 \\
(0.38)\end{array}$ & $\begin{array}{l}0.027 \\
(0.33)\end{array}$ & $\begin{array}{l}0.133 \\
(1.15)\end{array}$ & $\begin{array}{l}-0.079 \\
(0.84)\end{array}$ & $\begin{array}{c}-0.327 \\
(2.45)^{*}\end{array}$ \\
\hline Observations & 1,878 & & & 1,643 & & \\
\hline
\end{tabular}

Source: SOEP, 1993-2004

Sample: German full-time employees, age 20-60

Note: The regression model is full-specified, independent variables include worker and firm characteristics as well as region and year dummies. Absolute value of $t$ statistics in parentheses, ${ }^{*}$ significant at $5 \%$; ** significant at $1 \%$.

\footnotetext{
${ }^{29} \mathrm{We}$ additionally estimated the signaling effect of unpaid overtime on average earnings within the two and three subsequent years. Since the coefficients were comparable in size and significance, the particular results are not displayed here.
} 
For West German workers, unpaid hours on the 39 hours margin and next year's earnings are positively associated in the pooled OLS and in the random effects specification. However, the results of the fixed effects model are only significant at the $10 \%$ level for unpaid overtime at the 44 hours threshold. For East German workers, the negative signaling effect of unpaid extra hours at the 45 hours threshold prevails, leading to a $28 \%$ decrease in earnings in the subsequent year. This result is not in line with the overtime signaling model. Yet, unpaid overtime might still contain a short-term signaling component, which does not last to the following year. The evidence is stronger against the theory of deferred compensation, according to which current unpaid hours should be compensated in the future. This is clearly rejected by these results, which reveal no deferred compensation for a marginal unpaid extra hour, and even a "deferred punishment" for East German workers.

\subsubsection{White-Collar Workers}

An additional extension is the focus on white collar workers, since unpaid overtime hours are more prevalent among this worker group. This might be attributed to the fact that blue-collar workers are more strongly affected by binding wages and collectively bargained working hours. The incidence and number of unpaid hours of blue-collar workers might also be relatively low due to their different job characteristics, since these workers are less likely to have leadership roles and a higher certainty about the time to complete job tasks. Since there is more certainty on their value to the firm, there is not as much scope for signaling as it might be for white-collar workers. This reasoning is consistent with Cowling (2001) who finds that performance-related pay systems are implemented in workplaces, where output can be easily measured. He points out that blue-collar workers, such as plant and machine operators, and workers with short and repetitive tasks are more likely to receive performance-related pay, which restricts the possibilities to signal high value to the firm. Table 7 shows that the random effects specification yields a positive signaling effect for West German workers with unpaid overtime on the 39 hours, 40 hours, and 44 hours margin. However, in the fixed effects model, which is according to the Hausman test the preferred specification, the results are very similar to the main part of the analysis above. Evidence for overtime signaling is found for West German white-collar workers at the 44 hours threshold, which implies an increase in monthly income by $22 \%$. However, in East Germany, working unpaid hours at a level of 45 weekly hours, seems to be a negative signal, which is associated with a $20 \%$ reduction in monthly earnings. 
Table 7: DD Estimates of the Impact of Unpaid Overtime on Earnings for White-Collar Workers

\begin{tabular}{|c|c|c|c|c|}
\hline & \multicolumn{2}{|c|}{ West sample } & \multicolumn{2}{|c|}{ East sample } \\
\hline & $\begin{array}{l}\text { Random } \\
\text { Effects }\end{array}$ & $\begin{array}{c}\text { Fixed } \\
\text { Effects }\end{array}$ & $\begin{array}{l}\text { Random } \\
\text { Effects }\end{array}$ & $\begin{array}{l}\text { Fixed } \\
\text { Effects }\end{array}$ \\
\hline Overtime Threshold: 39 & $\begin{array}{c}0.080 \\
(2.32)^{*}\end{array}$ & $\begin{array}{l}0.045 \\
(1.26)\end{array}$ & - & - \\
\hline Observations & 3,766 & & & \\
\hline Overtime Threshold: 40 & $\begin{array}{c}0.037 \\
(2.39)^{*}\end{array}$ & $\begin{array}{l}0.020 \\
(1.22)\end{array}$ & $\begin{array}{l}-0.024 \\
(0.52)\end{array}$ & $\begin{array}{c}-0.013 \\
(0.29)\end{array}$ \\
\hline Observations & 4,359 & & 3,222 & \\
\hline Overtime Threshold: 41 & $\begin{array}{l}0.007 \\
(0.17)\end{array}$ & $\begin{array}{l}-0.027 \\
(0.62)\end{array}$ & $\begin{array}{l}-0.044 \\
(0.73)\end{array}$ & $\begin{array}{l}-0.102 \\
(1.50)\end{array}$ \\
\hline Observations & 2,150 & & 1,501 & \\
\hline Overtime Threshold: 42 & $\begin{array}{l}0.052 \\
(1.40)\end{array}$ & $\begin{array}{l}0.074 \\
(1.78)\end{array}$ & $\begin{array}{l}0.003 \\
(0.08)\end{array}$ & $\begin{array}{l}-0.007 \\
(0.19)\end{array}$ \\
\hline Observations & 2,524 & & 1,860 & \\
\hline Overtime Threshold: 43 & $\begin{array}{l}0.054 \\
(1.23)\end{array}$ & $\begin{array}{c}0.082 \\
(1.78)\end{array}$ & $\begin{array}{l}-0.032 \\
(0.74)\end{array}$ & $\begin{array}{l}-0.062 \\
(1.27)\end{array}$ \\
\hline Observations & 1,960 & & 1,540 & \\
\hline Overtime Threshold: 44 & $\begin{array}{c}0.122 \\
(2.17)^{*}\end{array}$ & $\begin{array}{c}0.195 \\
(3.29)^{* *}\end{array}$ & $\begin{array}{l}0.007 \\
(0.14)\end{array}$ & $\begin{array}{l}-0.052 \\
(0.88)\end{array}$ \\
\hline Observations & 1,655 & & 1,272 & \\
\hline Overtime Threshold: 45 & $\begin{array}{l}0.083 \\
(1.22)\end{array}$ & $\begin{array}{l}0.098 \\
(1.39)\end{array}$ & $\begin{array}{l}-0.025 \\
(0.39)\end{array}$ & $\begin{array}{c}-0.225 \\
(2.90)^{* *}\end{array}$ \\
\hline Observations & 2,308 & & 1,651 & \\
\hline
\end{tabular}

Source: SOEP, 1993-2004

Sample: German full-time employees, age 20-60

Note: The regression model is full-specified, independent variables include worker and firm characteristics as well as region and year dummies. Absolute value of $t$ statistics in parentheses,

* significant at $5 \%$;* significant at $1 \%$.

\subsubsection{Workers with Short Tenure}

Another check of robustness is to conduct the analysis only for workers with short tenure, since a signal is likely to be of greater value in the early period of an employment relationship, when there is greater uncertainty about the worker's true product. Since we cannot restrict our sample to recent job changers due to the problem of too few observations, we conduct the analysis for workers who changed their job recently within the last five years. In the West German sample, about $37 \%$ of the workers have five or less years of tenure, whereas this percentage is $48 \%$ in the East German sample. The estimates for workers with short tenure in Table 8 show that the restriction of the sample to workers who are relatively new in their firms leads to a change in the size and significance of some of the coefficients. ${ }^{30}$

\footnotetext{
${ }^{30} \mathrm{We}$ also included interaction terms of tenure and the treatment effect, which were however barely significant and very close to zero.
} 
In the estimates for West German workers, the formerly highly significant treatment effect on the 44 hours margin is now merely significant at the $10 \%$ level. At the same time, unpaid overtime now has a positive signaling value at the 40 hours threshold, and is linked to $10 \%$ higher monthly earnings. Unpaid overtime on the 45 hours margin now has a positive and strong signaling value for East German workers in the random effects model, but becomes negative and insignificant in the fixed effects specification, which is again superior to the random effects model according to the Hausman specification test. This indicates that unobserved characteristics which are correlated with the unpaid overtime have a positive earnings effect for East German workers with short tenure.

Table 8: DD Estimates of the Impact of Unpaid Overtime on Earnings for Workers with Short Tenure

\begin{tabular}{|c|c|c|c|c|}
\hline & \multicolumn{2}{|c|}{ West sample } & \multicolumn{2}{|c|}{ East sample } \\
\hline & $\begin{array}{l}\text { Random } \\
\text { Effects }\end{array}$ & $\begin{array}{c}\text { Fixed } \\
\text { Effects }\end{array}$ & $\begin{array}{l}\text { Random } \\
\text { Effects }\end{array}$ & $\begin{array}{c}\text { Fixed } \\
\text { Effects }\end{array}$ \\
\hline Overtime Threshold: 39 & $\begin{array}{l}0.018 \\
(0.29)\end{array}$ & $\begin{array}{l}-0.040 \\
(0.51)\end{array}$ & - & - \\
\hline Observations & 1,713 & & & \\
\hline Overtime Threshold: 40 & $\begin{array}{c}0.072 \\
(2.50)^{*}\end{array}$ & $\begin{array}{c}0.093 \\
(2.86)^{* *}\end{array}$ & $\begin{array}{l}-0.028 \\
(0.47)\end{array}$ & $\begin{array}{l}-0.045 \\
(0.62)\end{array}$ \\
\hline Observations & 2,408 & & 2,310 & \\
\hline Overtime Threshold: 41 & $\begin{array}{c}0.033 \\
(0.52)\end{array}$ & $\begin{array}{l}0.029 \\
(0.37)\end{array}$ & $\begin{array}{l}-0.037 \\
(0.46)\end{array}$ & $\begin{array}{l}0.014 \\
(0.13)\end{array}$ \\
\hline Observations & 1,037 & & 964 & \\
\hline Overtime Threshold: 42 & $\begin{array}{c}-0.050 \\
(0.95)\end{array}$ & $\begin{array}{l}-0.021 \\
(0.32)\end{array}$ & $\begin{array}{l}0.035 \\
(0.76)\end{array}$ & $\begin{array}{l}0.037 \\
(0.65)\end{array}$ \\
\hline Observations & 1,238 & 1238 & 1,203 & \\
\hline Overtime Threshold: 43 & $\begin{array}{l}-0.045 \\
(0.69)\end{array}$ & $\begin{array}{l}0.009 \\
(0.12)\end{array}$ & $\begin{array}{l}-0.038 \\
(0.64)\end{array}$ & $\begin{array}{l}-0.093 \\
(1.20)\end{array}$ \\
\hline Observations & 999 & & 1,003 & \\
\hline Overtime Threshold: 44 & $\begin{array}{l}0.025 \\
(0.30)\end{array}$ & $\begin{array}{l}0.156 \\
(1.56)\end{array}$ & $\begin{array}{l}0.015 \\
(0.21)\end{array}$ & $\begin{array}{l}0.010 \\
(0.11)\end{array}$ \\
\hline Observations & 827 & & 827 & \\
\hline Overtime Threshold: 45 & $\begin{array}{c}-0.036 \\
(0.43)\end{array}$ & $\begin{array}{l}0.078 \\
(0.78)\end{array}$ & $\begin{array}{c}0.322 \\
(3.13)^{* *}\end{array}$ & $\begin{array}{l}-0.026 \\
(0.93)\end{array}$ \\
\hline Observations & 1,285 & & 1,277 & \\
\hline
\end{tabular}

Source: SOEP, 1993-2004

Sample: German full-time employees, age 20-60

Note: The regression model is full-specified, independent variables include worker and firm characteristics as well as region and year dummies. Absolute value of $t$ statistics in parentheses, *significant at 5\%; ** significant at $1 \%$. 


\subsubsection{Alternative Testing Strategies}

There are other testing strategies in the educational signaling context, which might be borrowed to test the overtime signaling model against competing theories. ${ }^{31}$ The general strategy is to start from a separating equilibrium and to investigate whether exogenous changes which directly affect only one group of workers, e.g. low-value workers, lead to reactions of not directly affected workers. Whether high-value workers try to separate from low-value workers by the means of unpaid overtime might be investigated by considering the reaction of high-value workers to exogenous changes that directly affect only low-value workers (Lang and Kropp, 1986). This might be analyzed by observing collectively bargained working time reductions, which make it easier to perform extra hours also for low-value workers due to a downward shift of the overtime threshold. An increase in unpaid hours of high-value workers who already worked longer hours before the change, might support the overtime signaling theory. ${ }^{32}$ Furthermore, one might analyze whether low-value workers try to mimic high-value workers (Bedard, 2001). For instance, if high-value workers are constrained in obtaining the overtime signal, e.g. by legal limits, low-value workers will try to pool with high-value workers on the constrained high-value level of the signal. However, if high-value workers have unrestricted access to the signal, low-value workers will not obtain any overtime at all because the quality of the lower level of the signal is diluted by the presence of higher signaling levels. Providing low levels of the signal is therefore not worth the cost to invest in overtime. This might be tested by analyzing different environments, which imply different restrictions on the signal, e.g. unionized firms versus others, or countries with differing overtime regulations. ${ }^{33}$ Albrecht (1981) argues that employers will rely more on the signal when less is otherwise known. Therefore, one might further investigate unpaid extra hours related to other sources of information on worker value. This might be achieved by investigating tenure effects more closely, as over time the worker is likely to build a reputation in his firm, which narrows the scope for signaling. ${ }^{34}$ If overtime is in fact used as a signaling device, one should be able to observe restart effects, i.e. higher levels of overtime, when workers change their workplaces. However, these potential tests are left to future research.

\footnotetext{
${ }^{31}$ Lang and Kropp (1986), Bedard (2001), and Albrecht (1981) are some of them. For an overview of further studies, see Weiss (1995).

${ }^{32}$ This, of course, requires to control for a number of other factors, such as labor demand effects.

${ }^{33}$ This testing strategy might for example be applied to the comparison of overtime in Germany and Great Britain, as there is stronger surveillance of overtime in Germany through unions and works councils. At the same time, workers in Great Britain put in much longer hours.

${ }^{34}$ This analysis would require to distinguish between two effects which are difficult to separate. A firm might rely less on overtime as a signal, the longer the tenure because more is otherwise known, given constant overtime levels. However, workers might decrease their overtime level in later periods, either because they expect the firm to rely less on the overtime signal, or for other reasons.
} 


\section{Conclusion}

This paper adds to the various reasons for the worker's supply of overtime, and provides an explanation for the empirically proven relationship between overtime working and positive future outcomes, as pay rises or promotions. We extend Spence's (1973) signaling model and assume asymmetric information within the firm, which might arise from monitoring being too costly or hardly possible to implement. In our model of internal signaling the worker signals his value to the employer by working hours beyond the standard workweek. We derived the conditions for a separating equilibrium, in which high-value workers choose to work more overtime than low-value workers, and for a pooling equilibrium. We showed possible welfare effects which are ambiguous due to the trade-off between information revelation by means of signaling, and optimal working hours, since it is costly for workers to invest in signaling activities. The results above demonstrated that the outcome of a separating or pooling equilibrium depends on the firm's beliefs about the worker's value, which is derived from the observed level of overtime. The single-crossing property, i.e. the inverse relation between the worker's value and his disutility of working overtime is necessary, but not sufficient to ensure that low-value workers are deterred from pretending to be of a high-value type.

The aim of the empirical part of the analysis was to find out whether overtime has in fact a signaling component. We investigated whether earnings differentials can be partially traced back to the sorting mechanism of unpaid overtime, by using a quasi-experiment, in which the signal is randomly assigned to workers, which have otherwise identical expected productivity. Therefore, we used variations in collectively bargained hours between industries, which imply different overtime thresholds for workers with the same number of actual hours. To net out any industry differentials reflected in earnings, we applied a difference-in-differences estimator. Using data from the SOEP data for the years 1993 to 2004, we found support for the signaling hypothesis for West German workers, whereas negative signaling was found to prevail in East Germany. While for West German workers on the margin of 43 and 44 actual working hours, the signaling value of unpaid overtime is associated with an increase in earnings by $10 \%$ and $17 \%$, workers in East Germany at the 45 hours margin find the signaling value of unpaid overtime to lower their monthly income by $22 \%$. These findings were fairly robust to variations in the treatment group and to restricting the sample to white-collar workers only. However, no effects were found in the analysis of workers with short tenure, and on future earnings. Although we did not find evidence of systematic movements of workers from high to low hours jobs, potential endogeneity bias remains a main issue. In addition to workers self-selecting into jobs with certain contractual hours, individual behavior might be directly influenced by the differences in overtime thresholds in a systematic way. Further investigation of 
this bias includes observing how workers with a stable amount of actual hours at the same employer react to exogenous changes in their contracted working time. However, one should keep in mind that the realized overtime level reflects both labor supply and demand effects. Further investigation of this issue should hence take into account both sides of the labor market.

The findings of a positive relationship between marginal unpaid overtime hours and earnings for West German workers revealed that the theory of human capital, deferred compensation, or gift exchange are not capable of entirely explaining earnings differentials between workers with a different amount of working hours. The component of overtime hours, which is not used productively, but still yields an earnings premium, is evidence against the human capital explanation. Furthermore, the findings are not in line with the theory of deferred compensation, according to which there should be no correlation between current unpaid hours and current earnings, but significant effects on earnings in future periods. The finding that the value of an unpaid overtime hour is higher than of a contractual working hour might also be interpreted as gift exchange. However, according to the theory of gift exchange, the firm pays a higher wage to induce the worker to increase his working hours, effort and productivity, and overall output. Therefore, actual working hours should be roughly remunerated with the same earnings, as there is no explanation why firms should provide a greater gift to their workers than the one they receive. The overall finding is, therefore, that the hypothesis of a signaling component in unpaid overtime hours cannot be rejected.

Still, the puzzle that unpaid overtime workers in East Germany send a negative signal to their employers, while their West German colleagues are rewarded for unpaid extra hours, remains to be solved. Of course, every employer is likely to interpret the overtime signal differently, and while some employers might foster a long hours culture in their company, others might try to discourage extreme working hours in order to have a homogeneous workforce. However, the findings of a negative effect of unpaid overtime on the 45 hours margin was fairly robust, and the effect averaged over all employers in East Germany might be negative for other reasons. In terms of the overtime signaling model, firms take unpaid overtime as a sign for workers being of a low value, i.e. that their productivity is lower. This would be in line with one of the reasons for unpaid work named by Bell and Hart (1999). Unpaid hours might be used by unproductive workers to catch up with their more productive colleagues, and to understate the working time actually taken in order to build a good reputation. However, if employers observe these unpaid hours, they might infer lower productivity of these workers and pay them a lower wage, which corresponds to their hourly productivity. The findings of a negative signaling effect for East German workers are also 
consistent with the countersignaling theory of Feltovich, Harbaugh, and To (2001). They show that if signaling information is noisy, high-type workers choose not to signal, since signaling is perceived as sign of insecurity, whereas countersignaling, i.e. not to invest in signaling activities, may be interpreted as a sign of confidence. As the countersignaling equilibrium has implications that are inverse to those in standard signaling models, the negative signal in East Germany might be interpreted in this way. High-value workers choose not to work overtime, since the supply of unpaid hours might signal lower quality to the firms. This view opens a whole field of new research and needs further investigation.

However, the value of unpaid overtime hours being lower than that of actual hours worked by East German workers might also indicate that different types of working hours are not equally productive, regardless of the value-type of the worker. This would be consistent with the hypothesis that workers use unpaid hours merely to "present" themselves at the workplace. Furthermore, it might be the case that unpaid and paid working hours are equally productive, but that their productivity is not equally remunerated. One reason could be that unpaid overtime hours on the margin are more prevalent in firms which are close to a shut down, where workers are more likely to make wage concessions. Therefore, the consideration of firm characteristics would be required for a further analysis of the negative effect of marginal unpaid overtime in East Germany.

A number of additional analyses are indispensable in order to investigate in depth the meaning of internal signaling in firms with asymmetric information. One promising extension would be to investigate nonlinear effects of overtime hours, since it might well be the case that overtime signals high value at a certain level, but lower productivity at another level. Extremely long hours might also be evaluated negatively by employers if they deviate too much from the norm, as firms might have an interest in a homogenous workforce to foster a pleasant work atmosphere and to prevent "rat races" in the workplace. Furthermore, variations in the signaling effect for different worker groups might be analyzed using a difference-in-difference-in-differences (DDD) estimator. Gender differences might for instance be exploited, or differences in the treatment effect between occupation groups, which might be achieved by using more waves of the SOEP for the West German sample. Future research should hence be directed towards workers whose output can only hardly be measured. These workers are more likely to be evaluated on the grounds of subjective assessments, which might induce inefficient behavioral responses (Prendergast, 1999). An evaluation of the workers' quality other than by observed overtime levels could eventually entail welfare-enhancing effects. 


\section{Appendix}

Table A1: $\quad$ Summary Statistics of Variables Used in the DD Estimation

\begin{tabular}{|c|c|c|c|}
\hline \multirow[b]{2}{*}{ Variable } & \multirow[b]{2}{*}{ Description } & \multicolumn{2}{|c|}{ Mean (SD) } \\
\hline & & West & East \\
\hline & Dependent Variable & & \\
\hline \multirow[t]{2}{*}{ Lngrinc } & Log gross monthly income in Euros & $7.79(0.37)$ & $7.43(0.36)$ \\
\hline & Socio-Demographic Variables & & \\
\hline Age & Age in years & $38.35(9.94)$ & $40.34(9.72)$ \\
\hline Sex & Sex: $1=$ female, male $=0$ & 0.33 & 0.45 \\
\hline \multirow[t]{2}{*}{ Married } & Marital status: $1=$ married or cohabiting, else $=0$ & 0.84 & 0.89 \\
\hline & Wage, Education and Work Experience & & \\
\hline Edu & Length of education in years & $12.04(2.45)$ & $12.68(2.30)$ \\
\hline Tenure & Work experience at the same employer in years & $10.55(9.23)$ & $8.72(8.89)$ \\
\hline \multirow[t]{2}{*}{ Expfull } & Previous work experience as full-time employee in years & $17.60(10.9)$ & $20.04(9.88)$ \\
\hline & Job Characteristics & & \\
\hline Tempjob & Temporary job: $1=$ yes, no $=0$ & 0.04 & 0.06 \\
\hline Public & Public sector: $1=y e s$, no $=0$ & 0.21 & 0.32 \\
\hline Occ1 1 & Occupation: $1=$ Manager, else $=0$ & 0.05 & 0.04 \\
\hline Occ2 & Occupation: $1=$ Professional, else $=0$ & 0.13 & 0.13 \\
\hline Occ3 & Occupation: $1=$ Technician, else $=0$ & 0.25 & 0.23 \\
\hline Occ4 & Occupation: $1=$ Clerk, else $=0$ & 0.16 & 0.13 \\
\hline Occ5 & Occupation: $1=$ Service/Sales worker, else $=0$ & 0.06 & 0.08 \\
\hline Occ6 & Occupation: $1=$ Craft worker, else $=0$ & 0.21 & 0.26 \\
\hline Occ7 & Occupation: $1=$ Plant $/$ machine operator, else $=0$ & 0.08 & 0.08 \\
\hline Occ8 & Occupation: $1=$ Elementary occupation, else $=0$ & 0.04 & 0.06 \\
\hline Bluecol & Blue-collar worker $=1$, else $=0$ & 0.34 & 0.43 \\
\hline Bluecol0 & Blue-collar worker: $1=$ unskilled, else $=0 ;$ Reference category & 0.01 & 0.01 \\
\hline Bluecol1 & Blue-collar worker: $1=$ skilled, else $=0$ & 0.02 & 0.03 \\
\hline Bluecol2 & Blue-collar worker: $1=$ semiskilled, else $=0$ & 0.07 & 0.08 \\
\hline Bluecol3 & Blue-collar worker: $1=$ foreman, else $=0$ & 0.34 & 0.27 \\
\hline Bluecol4 & Blue-collar worker: $1=$ master, else $=0$ & 0.20 & 0.17 \\
\hline Whiteco0 & White-collar worker: $1=$ foreman, else $=0$; Reference category & 0.02 & 0.01 \\
\hline Whiteco1 & White-collar worker: $1=$ without vocational training, else $=0$ & 0.01 & 0.13 \\
\hline Whiteco2 & White-collar worker: $1=$ with vocational training, else $=0$ & 0.10 & 0.09 \\
\hline Whiteco3 & White-collar worker: $1=$ qualified occupation, else $=0$ & 0.19 & 0.27 \\
\hline Whiteco4 & White-collar worker: $1=$ highly qualified occupation, else $=0$ & 0.03 & 0.04 \\
\hline \multirow[t]{2}{*}{ Whiteco5 } & White-collar worker: $1=$ executive function, else $=0$ & 0.01 & 0.02 \\
\hline & Industry (Reference Category: All Other Branches) & & \\
\hline Branch1 & Branch: $1=$ Mining, oil, and gas, else $=0$ & 0.00 & 0.01 \\
\hline Branch2 & Branch: $1=$ Textiles, else $=0$ & 0.01 & 0.01 \\
\hline Branch3 & Branch: $1=$ Wood and Paper, else $=0$ & 0.03 & 0.02 \\
\hline Branch4 & Branch: $1=$ Chemicals, else $=0$ & 0.07 & 0.04 \\
\hline Branch5 & Branch: $1=$ Metal, else $=0$ & 0.08 & 0.06 \\
\hline Branch6 & Branch: $1=$ Vehicle and engine construction, else $=0$ & 0.15 & 0.07 \\
\hline Branch7 & Branch: $1=$ Energy $/$ Water, else $=0$ & 0.02 & 0.03 \\
\hline Branch 8 & Branch: $1=$ Construction, else $=0$ & 0.07 & 0.14 \\
\hline Branch9 & Branch: $1=$ Wholesale and retail, else $=0$ & 0.12 & 0.10 \\
\hline Branch10 & Branch: $1=$ Hotel and restaurant, else $=0$ & 0.01 & 0.01 \\
\hline
\end{tabular}




\begin{tabular}{|c|c|c|c|}
\hline Branch11 & Branch: $1=$ Transport, else $=0$ & 0.04 & 0.08 \\
\hline Branch12 & Branch: $1=$ Banking and insurance, else $=0$ & 0.07 & 0.04 \\
\hline Branch13 & Branch: $1=$ Health sector, else $=0$ & 0.09 & 0.11 \\
\hline \multirow[t]{2}{*}{ Branch14 } & Branch: $1=$ Other services, else $=0$ & 0.14 & 0.21 \\
\hline & Firm Size & & \\
\hline Size0 & Firm size $<5$ employees; Reference category & 0.04 & 0.07 \\
\hline Size 1 & Firm size $>5$ and $<20$ employees & 0.13 & 0.18 \\
\hline Size2 & Firm size $>20$ and $<200$ employees & 0.27 & 0.34 \\
\hline Size3 & Firm size $>200$ and $<2000$ employees & 0.27 & 0.23 \\
\hline \multirow[t]{2}{*}{ Size4 } & Firm size $>2000$ employees & 0.29 & 0.17 \\
\hline & Treatment Groups & & \\
\hline Treat 40 & Actual weekly hours: $1=40,0=$ above $40 \&$ unpaid overtime & 0.63 & 0.78 \\
\hline Treat41 & Actual weekly hours: $1=41,0=$ above $41 \&$ unpaid overtime & 0.26 & 0.24 \\
\hline Treat42 & Actual weekly hours: $1=42,0=$ above $42 \&$ unpaid overtime & 0.30 & 0.36 \\
\hline Treat43 & Actual weekly hours: $1=43,0=$ above $43 \&$ unpaid overtime & 0.23 & 0.22 \\
\hline Treat44 & Actual weekly hours: $1=44,0=$ above $44 \&$ unpaid overtime & 0.17 & 0.25 \\
\hline \multirow[t]{2}{*}{ Treat45 } & Actual weekly hours: $1=45,0=$ above $45 \&$ unpaid overtime & 0.44 & 0.43 \\
\hline & Treatment & & \\
\hline Low40 & Contractual weekly hours: $1=$ below 40 , else $=0$ & 0.25 & 0.05 \\
\hline Low41 & Contractual weekly hours: $1=$ below 41 , else $=0$ & 0.74 & 0.71 \\
\hline Low42 & Contractual weekly hours: $1=$ below 42 , else $=0$ & 0.75 & 0.66 \\
\hline Low43 & Contractual weekly hours: $1=$ below 43 , else $=0$ & 0.81 & 0.80 \\
\hline Low44 & Contractual weekly hours: $1=$ below 44 , else $=0$ & 0.87 & 0.76 \\
\hline \multirow[t]{2}{*}{ Low45 } & Contractual weekly hours: $1=$ below 45 , else $=0$ & 0.76 & 0.76 \\
\hline & Treated & & \\
\hline Low $40 *$ Treat 40 & $1=$ Actual hours $=40 \&$ contractual hours $<40$, else $=0$ & 0.04 & 0.00 \\
\hline Low $41 *$ Treat 41 & $1=$ Actual hours $=41 \&$ contractual hours $<41$, else $=0$ & 0.02 & 0.01 \\
\hline Low $42 *$ Teat 42 & $1=$ Actual hours $=42 \&$ contractual hours $<42$, else $=0$ & 0.07 & 0.05 \\
\hline Low $43 *$ Treat 43 & $1=$ Actual hours $=43 \&$ contractual hours $<43$, else $=0$ & 0.06 & 0.05 \\
\hline Low $44 *$ Treat 44 & $1=$ Actual hours $=44 \&$ contractual hours $<44$, else $=0$ & 0.05 & 0.03 \\
\hline \multirow[t]{2}{*}{ Low $45 *$ Treat 45} & $1=$ Actual hours $=45 \&$ contractual hours $<45$, else $=0$ & 0.21 & 0.19 \\
\hline & Observations & 16,779 & 10,533 \\
\hline
\end{tabular}

Source: SOEP, 1993-2004 (own calculations)

Sample: German male and female full-time employees, age 20-60, civil servants and self-employed persons excluded 
Table A2: DD Estimates of the Impact of Unpaid Overtime on Earnings

\begin{tabular}{|c|c|c|c|c|c|c|}
\hline \multirow[b]{2}{*}{$\begin{array}{l}\text { Dependent } \\
\text { variable: lngrinc }\end{array}$} & \multicolumn{3}{|c|}{ West sample } & \multicolumn{3}{|c|}{ East sample } \\
\hline & $\begin{array}{l}\text { Pooled } \\
\text { OLS }\end{array}$ & $\begin{array}{c}\text { Random } \\
\text { Effects }\end{array}$ & $\begin{array}{c}\text { Fixed } \\
\text { Effects }\end{array}$ & $\begin{array}{l}\text { Pooled } \\
\text { OLS }\end{array}$ & $\begin{array}{c}\text { Random } \\
\text { Effects }\end{array}$ & $\begin{array}{c}\text { Fixed } \\
\text { Effects }\end{array}$ \\
\hline \multirow[t]{2}{*}{ low40_treat40 } & 0.050 & 0.029 & 0.018 & -0.034 & -0.024 & -0.022 \\
\hline & $(2.39)^{*}$ & $(1.78)$ & (1.04) & $(0.70)$ & $(0.65)$ & $(0.57)$ \\
\hline \multirow[t]{2}{*}{ low40 } & -0.015 & -0.005 & -0.007 & 0.145 & 0.070 & 0.054 \\
\hline & $(1.25)$ & $(0.44)$ & $(0.63)$ & $(10.00)^{* *}$ & $(5.35)^{* *}$ & $(3.98)^{* *}$ \\
\hline \multirow[t]{2}{*}{ treat 40} & -0.093 & -0.052 & -0.030 & -0.044 & -0.007 & 0.011 \\
\hline & $(8.81)^{* *}$ & $(5.83)^{* *}$ & $(3.10)^{* *}$ & $(5.32)^{* *}$ & $(0.97)$ & $(1.38)$ \\
\hline \multirow{2}{*}{ age } & 0.006 & 0.016 & 0.047 & 0.019 & 0.019 & 0.048 \\
\hline & $(1.32)$ & $(3.16)^{* *}$ & $(6.03)^{* *}$ & $(4.70)^{* *}$ & $(3.92)^{* *}$ & $(7.09)^{* *}$ \\
\hline \multirow[t]{2}{*}{ age2 } & -0.000 & -0.000 & -0.000 & -0.000 & -0.000 & -0.000 \\
\hline & $(0.93)$ & $(2.68)^{* *}$ & $(3.99)^{* *}$ & $(4.39)^{* *}$ & $(3.66)^{* *}$ & $(3.41)^{* *}$ \\
\hline \multirow[t]{2}{*}{ married } & 0.024 & 0.018 & 0.010 & 0.026 & 0.009 & -0.011 \\
\hline & $(2.53)^{*}$ & $(2.00)^{*}$ & $(0.92)$ & $(2.97)^{* *}$ & $(0.93)$ & $(1.03)$ \\
\hline \multirow[t]{2}{*}{ sex } & -0.153 & -0.190 & 0.000 & -0.112 & -0.137 & 0.000 \\
\hline & $(16.58)^{* *}$ & $(13.74)^{* *}$ & (.) & $(15.97)^{* *}$ & $(11.82)^{* *}$ & (.) \\
\hline \multirow[t]{2}{*}{ edu } & 0.023 & 0.009 & -0.013 & 0.032 & 0.019 & -0.019 \\
\hline & $(1.50)$ & $(0.47)$ & $(0.51)$ & $(2.11)^{*}$ & $(0.94)$ & $(0.69)$ \\
\hline \multirow[t]{2}{*}{ edu2 } & 0.000 & 0.001 & 0.001 & -0.000 & 0.000 & 0.001 \\
\hline & $(0.12)$ & $(1.18)$ & $(0.64)$ & $(0.90)$ & $(0.67)$ & $(0.92)$ \\
\hline \multirow[t]{2}{*}{ expfull } & 0.025 & 0.024 & 0.035 & 0.007 & 0.006 & 0.025 \\
\hline & $(11.02)^{* *}$ & $(8.98)^{* *}$ & $(6.22)^{* *}$ & $(3.23)^{* *}$ & $(2.38)^{*}$ & $(5.40)^{* *}$ \\
\hline \multirow[t]{2}{*}{ expfull2 } & -0.001 & -0.000 & -0.000 & -0.000 & -0.000 & -0.000 \\
\hline & $(10.37)^{* *}$ & $(8.27)^{* *}$ & $(5.01)^{* *}$ & $(3.29)^{* *}$ & $(2.11)^{*}$ & $(2.10)^{*}$ \\
\hline \multirow[t]{2}{*}{ tenure } & 0.005 & 0.006 & 0.004 & 0.007 & 0.005 & 0.002 \\
\hline & $(4.18)^{* *}$ & $(4.79)^{* *}$ & $(2.39)^{*}$ & $(6.59)^{* *}$ & $(5.20)^{* *}$ & $(2.00)^{*}$ \\
\hline \multirow[t]{2}{*}{ tenure 2} & -0.000 & -0.000 & -0.000 & -0.000 & -0.000 & -0.000 \\
\hline & (1.74) & $(2.63)^{* *}$ & $(2.22)^{*}$ & $(4.30)^{* *}$ & $(2.58)^{* *}$ & $(0.52)$ \\
\hline size1 & 0.067 & 0.046 & 0.029 & 0.108 & 0.077 & 0.054 \\
\hline & $(3.99)^{* *}$ & $(2.95)^{* *}$ & (1.67) & $(8.86)^{* *}$ & $(6.85)^{* *}$ & $(4.34)^{* *}$ \\
\hline size2 & 0.134 & 0.098 & 0.065 & 0.191 & 0.145 & 0.099 \\
\hline & $(8.06)^{* *}$ & $(6.18)^{* *}$ & $(3.48)^{* *}$ & $(16.27)^{* *}$ & $(12.15)^{* *}$ & $(7.09)^{* *}$ \\
\hline size3 & 0.203 & 0.124 & 0.055 & 0.255 & 0.187 & 0.121 \\
\hline & $(11.61)^{* *}$ & $(7.31)^{* *}$ & $(2.73)^{* *}$ & $(20.33)^{* *}$ & $(14.47)^{* *}$ & $(7.97)^{* *}$ \\
\hline size4 & 0.253 & 0.161 & 0.065 & 0.276 & 0.200 & 0.122 \\
\hline & $(14.17)^{* *}$ & $(9.09)^{* *}$ & $(3.00)^{* *}$ & $(20.36)^{* *}$ & $(14.29)^{* *}$ & $(7.45)^{* *}$ \\
\hline public & -0.053 & -0.037 & -0.046 & 0.117 & 0.064 & 0.036 \\
\hline & $(3.97)^{* *}$ & $(2.82)^{* *}$ & $(2.83)^{* *}$ & $(14.20)^{* *}$ & $(7.52)^{* *}$ & $(3.70)^{* *}$ \\
\hline tempjob & -0.094 & -0.083 & -0.078 & -0.063 & -0.057 & -0.049 \\
\hline & $(5.50)^{* *}$ & $(5.93)^{* *}$ & $(5.08)^{* *}$ & $(5.14)^{* *}$ & $(5.40)^{* *}$ & $(4.18)^{* *}$ \\
\hline occ1 & 0.131 & 0.100 & 0.009 & 0.215 & 0.145 & 0.067 \\
\hline & $(5.22)^{* *}$ & $(4.59)^{* *}$ & $(0.36)$ & $(10.71)^{* *}$ & $(7.70)^{* *}$ & $(3.16)^{* *}$ \\
\hline occ 2 & 0.118 & 0.091 & -0.009 & 0.115 & 0.080 & 0.009 \\
\hline & $(4.83)^{* *}$ & $(4.19)^{* *}$ & $(0.37)$ & $(6.62)^{* *}$ & $(4.75)^{* *}$ & $(0.49)$ \\
\hline occ3 & 0.075 & 0.051 & -0.019 & 0.116 & 0.088 & 0.036 \\
\hline & $(3.29)^{* *}$ & $(2.51)^{*}$ & $(0.82)$ & $(7.40)^{* *}$ & $(5.69)^{* *}$ & $(1.99)^{*}$ \\
\hline occ4 & 0.032 & 0.019 & -0.042 & 0.058 & 0.062 & 0.022 \\
\hline & $(1.36)$ & $(0.91)$ & $(1.76)$ & $(3.51)^{* *}$ & $(3.78) * *$ & $(1.15)$ \\
\hline occ5 & -0.001 & -0.025 & -0.044 & 0.018 & 0.013 & -0.005 \\
\hline & $(0.02)$ & $(1.03)$ & $(1.51)$ & $(1.07)$ & $(0.73)$ & $(0.23)$ \\
\hline occ 6 & 0.047 & 0.033 & 0.002 & 0.088 & 0.062 & 0.046 \\
\hline & $(2.10)^{*}$ & $(1.65)$ & $(0.07)$ & $(6.08)^{* *}$ & $(4.07)^{* *}$ & $(2.58)^{* *}$ \\
\hline occ 7 & 0.073 & 0.043 & 0.008 & 0.083 & 0.054 & 0.033 \\
\hline & $(3.08)^{* *}$ & $(1.95)$ & $(0.29)$ & $(5.16)^{* *}$ & $(3.19)^{* *}$ & (1.68) \\
\hline bluecol & -0.299 & -0.229 & -0.053 & -0.201 & -0.183 & -0.113 \\
\hline & $(6.58)^{* *}$ & $(5.87)^{* *}$ & (1.18) & $(5.99)^{* *}$ & $(6.24) * *$ & $(3.52)^{* *}$ \\
\hline whitecol & -0.088 & -0.061 & 0.036 & -0.138 & -0.106 & -0.060 \\
\hline & $(2.40)^{*}$ & $(1.80)$ & $(0.93)$ & $(4.76)^{* *}$ & $(4.03)^{* *}$ & $(2.13)^{*}$ \\
\hline whiteco 2 & -0.091 & -0.047 & 0.013 & -0.091 & -0.059 & -0.030 \\
\hline
\end{tabular}




\begin{tabular}{|c|c|c|c|c|c|c|}
\hline & $(2.91)^{* *}$ & (1.65) & $(0.40)$ & $(3.44)^{* *}$ & $(2.52)^{*}$ & $(1.21)$ \\
\hline \multirow{2}{*}{ whiteco3 } & 0.026 & 0.013 & 0.016 & -0.034 & -0.019 & -0.015 \\
\hline & $(0.93)$ & $(0.48)$ & $(0.53)$ & $(1.36)$ & $(0.83)$ & $(0.61)$ \\
\hline \multirow[t]{2}{*}{ whiteco 4} & 0.233 & 0.143 & 0.083 & 0.151 & 0.061 & -0.002 \\
\hline & $(8.35)^{* *}$ & $(5.45)^{* *}$ & $(2.78)^{* *}$ & $(5.83)^{* *}$ & $(2.63)^{* *}$ & $(0.08)$ \\
\hline \multirow[t]{2}{*}{ whiteco5 } & 0.458 & 0.268 & 0.186 & 0.384 & 0.257 & 0.172 \\
\hline & $(14.32)^{* *}$ & $(8.97)^{* *}$ & $(5.53)^{* *}$ & $(11.13)^{* *}$ & $(8.07)^{* *}$ & $(4.99)^{* *}$ \\
\hline \multirow[t]{2}{*}{ bluecol1 } & 0.102 & 0.036 & 0.004 & -0.008 & 0.014 & 0.015 \\
\hline & $(2.73)^{* *}$ & $(1.28)$ & $(0.15)$ & $(0.36)$ & $(0.75)$ & $(0.79)$ \\
\hline \multirow[t]{2}{*}{ bluecol2 } & 0.192 & 0.108 & 0.020 & 0.047 & 0.047 & 0.033 \\
\hline & $(5.10)^{* *}$ & $(3.60)^{* *}$ & $(0.60)$ & $(2.05)^{*}$ & $(2.42)^{*}$ & $(1.55)$ \\
\hline \multirow[t]{2}{*}{ bluecol3 } & 0.258 & 0.165 & 0.041 & 0.102 & 0.076 & 0.049 \\
\hline & $(5.84)^{* *}$ & $(4.42)^{* *}$ & $(0.95)$ & $(3.71)^{* *}$ & $(3.24)^{* *}$ & $(1.92)$ \\
\hline \multirow[t]{2}{*}{ bluecol4 } & 0.321 & 0.225 & 0.053 & 0.168 & 0.143 & 0.077 \\
\hline & $(6.91)^{* *}$ & $(5.98)^{* *}$ & $(1.24)$ & $(5.34)^{* *}$ & $(5.11)^{* *}$ & $(2.46)^{*}$ \\
\hline \multirow{2}{*}{ branch1 } & 0.026 & 0.044 & 0.047 & 0.119 & 0.051 & -0.029 \\
\hline & $(0.53)$ & $(0.96)$ & $(0.92)$ & $(4.25)^{* *}$ & (1.63) & $(0.73)$ \\
\hline \multirow[t]{2}{*}{ branch2 } & -0.177 & -0.102 & -0.056 & -0.115 & -0.028 & -0.001 \\
\hline & $(6.22)^{* *}$ & $(3.28)^{* *}$ & $(1.46)$ & $(4.30)^{* *}$ & $(0.92)$ & $(0.04)$ \\
\hline \multirow[t]{2}{*}{ branch3 } & -0.021 & 0.003 & 0.014 & -0.030 & -0.029 & -0.050 \\
\hline & $(0.86)$ & $(0.14)$ & $(0.48)$ & $(1.20)$ & (1.09) & $(1.64)$ \\
\hline \multirow[t]{2}{*}{ branch4 } & 0.050 & 0.027 & 0.005 & 0.042 & 0.003 & -0.002 \\
\hline & $(2.93)^{* *}$ & (1.57) & $(0.25)$ & $(2.44)^{*}$ & $(0.16)$ & $(0.07)$ \\
\hline \multirow{2}{*}{ branch5 } & 0.024 & 0.025 & 0.015 & 0.018 & -0.000 & 0.011 \\
\hline & (1.35) & (1.49) & $(0.79)$ & $(1.06)$ & $(0.01)$ & $(0.58)$ \\
\hline \multirow[t]{2}{*}{ branch6 } & 0.046 & 0.041 & 0.015 & 0.041 & 0.019 & 0.021 \\
\hline & $(3.30)^{* *}$ & $(3.12)^{* *}$ & (1.00) & $(2.64) * *$ & $(1.24)$ & $(1.25)$ \\
\hline \multirow[t]{2}{*}{ branch7 } & 0.068 & 0.077 & 0.038 & 0.092 & 0.080 & 0.011 \\
\hline & $(2.11)^{*}$ & $(2.26)^{*}$ & $(0.88)$ & $(4.18)^{* *}$ & $(3.15)^{* *}$ & $(0.35)$ \\
\hline branch8 & 0.012 & -0.005 & -0.018 & 0.103 & 0.065 & 0.040 \\
\hline & $(0.73)$ & $(0.30)$ & $(0.97)$ & $(7.69)^{* *}$ & $(4.85)^{* *}$ & $(2.61)^{* *}$ \\
\hline branch9 & -0.116 & -0.038 & 0.010 & -0.028 & -0.022 & -0.005 \\
\hline & $(8.24)^{* *}$ & $(2.91)^{* *}$ & $(0.70)$ & $(2.02)^{*}$ & $(1.58)$ & $(0.30)$ \\
\hline branch 10 & -0.163 & -0.082 & -0.023 & -0.075 & -0.062 & -0.013 \\
\hline & $(5.47)^{* *}$ & $(2.63) * *$ & $(0.56)$ & $(3.05)^{* *}$ & $(2.19)^{*}$ & $(0.35)$ \\
\hline branch11 & -0.074 & -0.027 & 0.001 & -0.003 & 0.006 & 0.047 \\
\hline & $(3.70)^{* *}$ & $(1.31)$ & $(0.03)$ & $(0.18)$ & $(0.37)$ & $(2.08)^{*}$ \\
\hline branch 12 & 0.049 & 0.036 & -0.019 & 0.109 & 0.086 & -0.016 \\
\hline & $(2.55)^{*}$ & $(1.80)$ & $(0.73)$ & $(5.56)^{* *}$ & $(3.40)^{* *}$ & $(0.43)$ \\
\hline branch13 & -0.064 & -0.054 & -0.065 & 0.056 & 0.049 & 0.022 \\
\hline & $(3.34)^{* *}$ & $(2.56)^{*}$ & $(2.04)^{*}$ & $(4.06)^{* *}$ & $(3.23)^{* *}$ & (1.18) \\
\hline branch14 & -0.045 & -0.027 & -0.020 & 0.011 & 0.027 & 0.015 \\
\hline & $(3.11)^{* *}$ & $(2.05)^{*}$ & (1.41) & $(0.84)$ & $(2.30)^{*}$ & $(1.17)$ \\
\hline year1994 & 0.005 & 0.015 & -0.006 & 0.106 & 0.112 & 0.073 \\
\hline & $(0.28)$ & $(1.32)$ & $(0.53)$ & $(9.04) * *$ & $(14.64)^{* *}$ & $(9.98)^{* *}$ \\
\hline year1995 & 0.037 & 0.042 & -0.011 & 0.164 & 0.163 & 0.082 \\
\hline & $(2.20)^{*}$ & $(3.77)^{* *}$ & (1.10) & $(13.76)^{* *}$ & $(20.37)^{* *}$ & $(11.05)^{* *}$ \\
\hline year1996 & 0.086 & 0.095 & 0.019 & 0.224 & 0.229 & 0.109 \\
\hline & $(4.93)^{* *}$ & $(8.17)^{* *}$ & $(1.86)$ & $(17.91)^{* *}$ & $(26.95) * *$ & $(14.05)^{* *}$ \\
\hline year1997 & 0.088 & 0.092 & -0.013 & 0.254 & 0.255 & 0.094 \\
\hline & $(5.28)^{* *}$ & $(8.15)^{* *}$ & $(1.31)$ & $(20.64)^{* *}$ & $(30.11)^{* *}$ & $(12.34)^{* *}$ \\
\hline year1998 & 0.078 & 0.083 & -0.047 & 0.256 & 0.263 & 0.064 \\
\hline & $(4.61)^{* *}$ & $(7.16)^{* *}$ & $(4.75)^{* *}$ & $(20.50)^{* *}$ & $(30.09)^{* *}$ & $(8.20)^{* *}$ \\
\hline year1999 & 0.108 & 0.120 & -0.039 & 0.268 & 0.286 & 0.049 \\
\hline & $(6.40)^{* *}$ & $(10.25)^{* *}$ & $(3.93)^{* *}$ & $(20.75)^{* *}$ & $(31.35)^{* *}$ & $(5.87)^{* *}$ \\
\hline year2000 & 0.120 & 0.135 & -0.079 & 0.300 & 0.308 & -0.010 \\
\hline & $(7.17)^{* *}$ & $(10.97)^{* *}$ & $(4.25)^{* *}$ & $(23.60)^{* *}$ & $(32.46)^{* *}$ & $(0.73)$ \\
\hline year2001 & 0.158 & 0.175 & -0.055 & 0.320 & 0.336 & -0.009 \\
\hline & $(8.66)^{* *}$ & $(13.37)^{* *}$ & $(3.40)^{* *}$ & $(22.04)^{* *}$ & $(31.61)^{* *}$ & $(0.70)$ \\
\hline year2002 & 0.183 & 0.200 & -0.040 & 0.360 & 0.361 & -0.012 \\
\hline & $(10.89)^{* *}$ & $(16.31)^{* *}$ & $(3.13)^{* *}$ & $(27.47)^{* *}$ & $(36.88)^{* *}$ & $(1.18)$ \\
\hline year2003 & 0.195 & 0.228 & -0.022 & 0.380 & 0.385 & -0.013 \\
\hline & $(11.27)^{* *}$ & $(18.15)^{* *}$ & $(2.01)^{*}$ & $(27.42)^{* *}$ & $(36.81)^{* *}$ & $(1.29)$ \\
\hline
\end{tabular}




\begin{tabular}{lcccccc} 
year2004 & 0.226 & 0.265 & 0.000 & 0.403 & 0.417 & 0.000 \\
& $(13.05)^{* *}$ & $(20.69)^{* *}$ & $()$. & $(28.66)^{* *}$ & $(38.29)^{* *}$ & $()$. \\
Constant & 6.849 & 6.725 & 6.283 & 6.116 & 6.344 & 5.357 \\
& $(49.71)^{* *}$ & $(43.01)^{* *}$ & $(27.86)^{* *}$ & $(47.50)^{* *}$ & $(39.21)^{* *}$ & $(23.14)^{* *}$ \\
R-squared & 0.72 & 0.70 & 0.48 & 0.64 & 0.61 & 0.48 \\
Observations & & 5031 & & & 6691 & \\
\hline
\end{tabular}

Source: SOEP, 1993-2004 (own calculations)

Sample: German male and female full-time employees, age 20-60, civil servants and self-employed persons excluded. Additional region dummies included. Robust $\mathrm{z}$ statistics in parentheses, * significant at 5\%; ** significant at $1 \%$ 


\section{Bibliography}

Akerlof, G.A. (1976): The Economics of Caste and of the Rat Race and Other Woeful Tales, The Quarterly Journal of Economics, 90 (4), 599-617.

Albrecht, J.W. (1981): A Procedure for Testing the Signalling Hypothesis, Journal of Public Economics, 15, 123-132.

Altonji, J.G., C.R. Pierret (1997): Employer Learning and the Signaling Value of Education, National Longitudinal Surveys, Discussion Paper, U.S. Department of Labor, Bureau of Labor Statistics.

Anger, Silke (2005a): Unpaid Overtime in Germany: Differences Between East and West, Journal of Applied Social Science Studies (Schmollers Jahrbuch), 125 (1), 17-21.

Anger, S. (2005b): Working Time as an Investment? - The Effects of Unpaid Overtime on Wages, Promotions and Layoffs, DIW Discussion Paper No. 535, German Institute for Economic Research, Berlin.

Banks, J.S., R.K. Sundaram (1998): Optimal Retention in Agency Problems, Journal of Economic Theory, 82 (2), 293-323.

Bedard, K. (2001): Human Capital versus Signaling Models: University Access and High School Dropouts, Journal of Political Economy, 109 (4), 749-775.

Bell, L., R.B. Freeman (2001): The Incentive for Working Hard. Explaining Hours Worked

Differences in the US and Germany, Labour Economics, 8 (2), 181-202.

Bell, D.N.F., R.A. Hart (1999): Unpaid work, Economica, 66, 271-290.

Bell, D.N.F., R.A. Hart (2003): How Important is Guaranteed or Institutionalised Overtime?, Institute for the Study of Labor (IZA), Discussion Paper No. 766.

Bell, D.N.F., R.A. Hart, O. Hübler, W. Schwerdt (2000): Paid and Unpaid Overtime Working in Germany and the UK, Institute for the Study of Labor (IZA), Discussion Paper No. 133.

Belman, D., J.S. Heywood (1997): Sheepskin Effects by Cohort: Implications of Job Matching in a Signaling Model, Oxford Economic Papers, 49, 623-637.

Böckerman, P., M. Jäntti (2004): Is Variation in Hours of Work Driven by Supply or Demand? Evidence from Finnish Manufacturing Industries, Labour Institute for Economic Research, Discussion Paper No. 196.

Booth, A.L., M. Francesconi, J. Frank (2003): A Sticky Floors Model of Promotion, Pay and Gender, European Economic Review, 47 (2), 295-322.

Bratti, M., S. Staffolani (2005): Effort-Based Career Opportunities and Working Time, Institute for the Study of Labor (IZA), Discussion Paper No. 1474. 
Bryan, M.L. (2004): Workers, Workplaces and Working Hours, Institute for Social and Economic Research (ISER), Working Paper No. 25, University of Essex.

Campbell, D., F. Green (2002): The Long-Term Pay-Off From Working Longer Hours, Department of Economics, Discussion Paper No. 02/05, University of Kent.

Campbell, I. (2002): Snatching at the Wind? Unpaid Overtime and Trade Unions in Australia, International Journal of Employment Studies, 10 (2), 109-156.

Cho, I.-K., D.M. Kreps (1987): Signaling Games and Stable Equilibria, The Quarterly Journal of Economics, 102 (2), 179-222.

Cowling, M. (2001): Fixed Wages or Productivity Pay: Evidence from 15 EU Countries, Small Business Economics, 16 (3), 191-204.

Engellandt, A., R. Riphahn (2003): Temporary Contracts and Employee Effort, Centre for Economic Policy Research (CEPR), Discussion Paper No. 4178.

Engellandt, A., R. Riphahn (2004): Incentive Effects of Bonus Payments: Evidence from an International Company, Institute for the Study of Labor (IZA), Discussion Paper No. 1229. European Commission (2003): Flexibility, Security and Quality in Work, Employment in Europe, Recent Trends and Prospects, Chapter 4, 79-114.

Feltovich, N., R. Harbaugh, T. To (2001): Too Cool for School? Signaling and Countersignaling, RAND Journal of Economics, 33 (4), 630-649.

Gibbons, R., L. Katz (1991): Layoffs and Lemons, Journal of Labor Economics, 9 (4), 351-380.

Gibbons, R., K.J. Murphy (1992): Optimal Incentive Contracts in the Presence of Career Concerns: Theory and Evidence, Journal of Political Economy, 100 (3), 468-505.

Greene, W.H. (2000): Econometric Analysis, Fourth Edition (London: Prentice-Hall International). Haisken-DeNew, J.P., J.R. Frick (2003): Desktop Companion to the German Socio-Economic Panel Study, German Institute for Economic Research (DIW), Berlin.

Heywood, J., O. Hübler, U. Jirjahn (1998): Variable Payment Schemes and Industrial Relations:

Evidence from Germany, Kyklos, Blackwell Publishing, 51 (2), 237-257.

Hunt, J. (1999): Has Work-Sharing Worked in Germany? The Quarterly Journal of Economics, 114 (1), 117-148.

Ichino, A., G. Muehlheusser (2003): How Often Should You Open the Door? Optimal Monitoring to Screen Heterogeneous Agents, Institute for the Study of Labor (IZA), Discussion Paper No. 987.

Ichino, A., R. Riphahn (2001): The Effect of Employment Protection on Worker Effort: A Comparison of Absenteeism During and After Probation, Institute for the Study of Labor (IZA), Discussion Paper No. 385. 
Jovanovic, B. (1979): Job Matching and the Theory of Turnover, Journal of Political Economy, 87 (5), 972-90.

Landers, R., J. Rebitzer, L. Taylor (1996): Rate Race Redux: Adverse Selection in the Determination of Work Hours in Law Firms, American Economic Review, 86, 3229-3248.

Lang, K., D. Kropp (1986): Human Capital versus Sorting: The Effects of Compulsory Attendance Laws, Quarterly Journal of Economics, 101(3), 609-624.

Lazear, E.P. (1981): Rank Order Tournaments as Optimum Labor Contracts, Journal of Political Economy, 89 (5), 841-861.

Meyer, B. (1995): Natural and Quasi-experiments in Economics, Journal of Business and Economic Statistics, 13 (2), 151-161.

Meyer, A., M. Wallette (2004): Absence of Absenteeism and Overtime Work - Signalling Factors for Temporary Workers?, mimeo.

Nagin, D., J. Rebitzer, S. Sander, L. Taylor (2002): Monitoring, Motivation and Management: The Determinants of Opportunistic Behavior in a Field Experiment, National Bureau of Economic Research (NBER), Working Paper No. 8811.

Pannenberg, M. (2005): Long-Term Effects of Unpaid Overtime, Evidence for West Germany, Scottish Journal of Political Economy, 52, 177-193.

Pierce, B. (1999): Compensation Inequality, Bureau of Labor Statistics, Working Paper No. 323, U.S. Department of Labor, Washington.

Prendergast, C. (1999): The Provision of Incentives in Firms, Journal of Economic Literature, 37, 763.

Simpson, R. (1998): Presenteeism, Power and Organisational Change: Long Hours as a Career Barrier and the Impact on the Working Lives of Women Managers, British Journal of Management, 9 (1), 471-522.

Sousa-Poza, A., A. Ziegler (2003): Asymmetric Information About Workers' Productivity as a Cause for Inefficient Long Working Hours, Labour Economics, 10 (6), 727-747.

Spence, M. (1973): Job Market Signaling, The Quarterly Journal of Economics, 87, 355-374. Spence, M. (1974): Market Signaling: Informational Transfer in Hiring and Related Screening Processes, Cambridge, MA: Harvard University Press.

Spence, M. (2002): Signaling in Retrospect and the Informational Structure of Markets, American Economic Review, 92 (3), 434-459.

Streb, J.M. (2002): Job Market Signaling under Two-Dimensional Asymmetric Information, Department of Economics, Working Paper, Universidad del DEMA, Buenos Aires.

Tyler, J.H., R.J. Murnane, J.B. Willett (2000): Estimating The Labor Market Signaling Value Of The GED, The Quarterly Journal of Economics, 115(2), 431-468. 
Weiss, A. (1995): Human Capital vs. Signalling Explanation of Wages, Journal of Economic Perspectives, 9 (4), 133-154.

Wooldridge, J.M. (2002): Econometric Analysis of Cross Section and Panel Data, MIT Press, Cambridge. 